\title{
Les transformations fonctionnelles de la cour et la culture du livre dans la Hongrie royale et en Transylvanie aux $\mathrm{XVI}^{\mathrm{e}}$ ET XVII ${ }^{\mathrm{e}}$ siècles
}

\author{
István Monok
}

Université de Szeged, Bibliothèque de l'Académie Hongroise des Sciences, Hungary

\section{ORIGINAL RESEARCH PAPER}

Received: August 27, 2020 • Accepted: September 29, 2020

Published online: June 22, 2021

(c) 2020 The Author(s)

\begin{abstract}
La cour royale de Mathias Corvin $(1443-1490 ; 1458-1490)$ et celle des rois Jagellons jouent jusqu'au XV siècle, dans la vie intellectuelle du royaume de Hongrie, un rôle comparable à celui des cours royales en Europe occidentale. Mais l'occupation de la capitale (Buda) par les Turcs (1541) et l'absence de souverain « national » transforment profondément le rôle des familles aristocratiques pour ce qui concerne tant l'organisation de la vie culturelle que la vie de l'Église. Parallèlement, la Réforme protestante progresse au $\mathrm{XVI}^{\mathrm{e}}$ siècle en Hongrie et en Transylvanie, cette dernière devenue une principauté pratiquement indépendante. Les nouveaux acteurs autour desquels se développe dès lors la vie culturelle dans le pays sont les grands aristocrates et les cours qu'ils réunissent à leur entour : les Bánffy, Batthyány, Nádasdy, Perényi, Rákóczi, Esterházy et quelques autres. En Transylvanie, le rôle de la cour princière reste dominant, grâce à sa richesse relative par rapport aux cours seigneuriales. Si l'aristocratie de Hongrie et de Transylvanie se convertit très majoritairement à la Réforme au XVI ${ }^{\mathrm{e}}$ siècle, la politique des Habsbourg et les progrès de la Contre-Réforme entraînent un vaste mouvement de reconversion, mais en Hongrie seulement, au XVII siècle. À la fin du siècle, ces territoires sont pleinement réintégrés dans les territoires des Habsbourg : dès lors, la question de la modernité se déploie de plus en plus nettement, à laquelle se joint la nouvelle problématique de l'identité collective, puis nationale.
\end{abstract}

\footnotetext{
*Corresponding author. E-mail: monok@mtak.hu
}

Cette recherche est soutenue par NKFIH/OTKA K 132770. 


\section{MOTS-CLEFS}

Europe centrale, Hongrie, Temps modernes, histoire du livre, histoire des bibliothèques, histoire de la lecture, histoire des mouvements intellectuels

La noblesse hongroise de la première modernité est souvent associée aux stéréotypes de l'inculture et de l'obscurantisme rétrograde. La présence de ce topos dans la pensée occidentale remonte à l'image péjorative qui s'est progressivement formée au sujet des Hongrois après la conquête du pays par les Ottomans et en particulier depuis l'apparition du « Tableau des Peuples »(Völkertafel). ${ }^{1}$ Le fait que le peuple hongrois ait adopté le christianisme, qu'il ait établi une Église comparable à celles des pays occidentaux et qu'il ait organisé son État selon les modèles les plus répandus, voire qu'il soit devenu une grande puissance européenne, n'a nullement affecté l'appréciation générale des Hongrois en tant que peuple sauvage, violent, cruel, glouton et ivrogne. Les $\mathrm{XVI}^{\mathrm{e}}$ et XVII ${ }^{\mathrm{e}}$ siècles, en revanche, ont vu le déclin de l'État hongrois. Ayant perdu du terrain dans la compétition entre les puissances, la Hongrie ne disposa plus que de ressources minimales pour faire fonctionner ses institutions étatiques, ecclésiastiques et culturelles. Soulignons aussi le fait qu'elle a vu se dérouler sur son territoire plusieurs campagnes militaires entraînant la destruction physique de certains établissements à vocation «culturelle » collective. Ces derniers - faute de pouvoir central et de volonté nationale - n'ont pu être rétablis ou reconstruits qu'en se conformant au programme édicté par les autorités (ecclésiastiques ou laïques) locales. Les institutions détruites furent par conséquent recréées avec de nouveaux contenus et, souvent, sous le signe d'une confession différente. ${ }^{2}$

Certes, les peuples occidentaux ne sont pas les seuls à avoir une opinion défavorable au sujet de la noblesse hongroise et de sa clientèle. La recherche hongroise elle-même est partagée lorsqu'il s'agit d'émettre un jugement d'ordre général.

-Ceux qui étudient l'histoire de l'illettrisme et de l'inscolarité ont l'embarras du choix lorsqu'ils cherchent les preuves du sous-développement culturel hongrois. Ce type de description présente le plus souvent la situation hongroise en tant que telle, comme un cas isolé, en l'absence de toute perspective comparatiste. ${ }^{3}$

-Les tenants de l'autre approche, celle des recherches consacrées à l'étude du livre et de la lecture, à l'histoire des bibliothèques et à celle des écoles, sont plus à même de mettre en valeur des aspects favorables de la culture hongroise. Ils adoptent volontiers le point de vue comparatif, même s'ils doivent admettre que la Hongrie n'a pas atteint, à l'époque, le niveau culturel des pays occidentaux. Dans notre présentation, nous nous efforcerons de traiter les deux aspects - celui de l'illettrisme et celui des lectures -, mais nous devons préciser que nous nous intéressons prioritairement à l'étude des lectures, du point de vue de leurs contenus. ${ }^{4}$

\footnotetext{
${ }^{1}$ Halmágyi 2009; Ötvös P. 1999; Köpeczi 1966; Köpeczi 1976; Etényi-Horn (szerk.), Portré és imázs. . [Portrait et image] 2008; Várkonyi Á. 2010; Kövér 2007.

${ }^{2}$ Péter K. 1989; Péter K. 1989a; Várkonyi Á. 1986; Várkonyi Á. 1989.

${ }^{3}$ Tóth I. Gy. 1987; Tóth I. Gy. 1993; Tóth I. Gy. 1996; Tóth I. Gy. 1996a; Tóth I. Gy. 2004. Ainsi que l'avis critique contre cette approche : Kristóf 1995; Kristóf 2002; Kristóf 2008; Kristóf 2008a, cf. Kristóf 1990.

${ }^{4}$ Soltész 1974; Berlász 1974; Csapodi 1984; Monok 2008; Monok 2011a.
} 
Commençons par souligner deux phénomènes de première importance.

Le premier concerne les revenus de la noblesse hongroise et transylvaine, ainsi que la stratification de cette couche sociale en fonction de la situation matérielle. Les grands propriétaires transylvains se trouvaient dans une situation très défavorable par rapport aux nobles de la Hongrie royale, ce qui s'explique par les conditions géographiques et économiques désavantageuses de leur environnement. Les vallées fertiles des fleuves du pays sicules, du Királyföld et de la Transylvanie proprement dite furent bien plus souvent frappées par des campagnes de dévastation que la Hongrie occidentale ou la Haute-Hongrie. D’autre part, la stratification sociale du peuple sicule était fondamentalement différente de celle que l'on trouvait en Hongrie royale : on peut dire, en règle générale, qu'elle était beaucoup plus pauvre. Le Sicule moyen se trouvait dans une condition misérable, ce qui explique la pauvreté de ses lectures et le caractère sous-développé des bibliothèques de la région. Certes, nous ne saurions nous limiter à une simplification abusive : au XVI ${ }^{\mathrm{e}}$ siècle, la plupart des chanceliers de Transylvanie furent des nobles ayant bénéficié d'une formation académique (notons tout de même qu'au cours du XVII siècle, la proportion de «clercs » parmi les chanceliers et les conseillers curiaux a baissé). Mais la condition de fortune n'était pas le seul facteur d'acculturation : l'évolution des possibilités de scolarisation et le fonctionnement du système institutionnel d'éducation - n'oublions pas les dégâts causés par la guerre de Quinze Ans et par les bouleversements politiques postérieurs à 1658 - exercèrent une énorme influence sur les pratiques culturelles des élites. ${ }^{5}$

L'autre facteur ayant influencé, de manière fondamentale, le niveau culturel de la noblesse (et de la société tout entière) est la faiblesse de la papeterie et de l'imprimerie locales, ainsi que l'absence presque complète des activités de librairie. Il s'agit bien évidemment d'abord d'un facteur paralysant l'achat des livres et l'enrichissement des bibliothèques, mais il y a plus : cela implique aussi que l'érudition de la haute noblesse était entièrement subordonnée aux goûts de la cour et aux intérêts commerciaux des « agents » du livre. ${ }^{6}$

Un colloque tenu à Venise en octobre 2008 a montré que le marché vénitien des œuvres d'art et des produits culturels à l'époque moderne exige une analyse fine. Les interventions ont étudié les transformations du goût caractérisant la première modernité, qu'il s'agisse de la vie musicale, du théâtre ou encore des achats et des collections de peintures, de sculptures et de livres. À Venise, les modifications du goût affectaient profondément le processus de création (il ne s'agit pas seulement pour nous d'une volonté de se conformer à la critique contemporaine). En Hongrie, rien de tel. ${ }^{7}$ Certes, nous pouvons observer, au milieu du XVII ${ }^{\mathrm{e}}$ siècle, une vague de création de collections, et l'on voit même émerger l'idée de fonder des musées. Les suzerains des cours seigneuriales de Hongrie occidentale (pensons à la famille Nádasdy, puis aux Batthyány et aux Esterházy) ne se contentaient plus d'employer les ingénieurs, architectes, peintres, sculpteurs, musiciens ou graveurs qui se trouvaient d'aventure disponibles ; au contraire, ils avaient des idées très précises sur l'image culturelle qu'ils souhaitaient donner à leur cour - comme en témoignent les changements observés dans les règlements curiaux. ${ }^{8}$ On n'oserait affirmer que la

\footnotetext{
${ }^{5}$ Balogh 2005; Tüdős 1998; Horn 2010.

${ }^{6}$ Bogdán 1963; Ecsedy 1999; Teutsch 1879-1892; Wiesner 1913; Tolnai 1986; Kókay 1990.

${ }^{7}$ CaféBábel, 14. kötet (recueil de données), 1994, Nr. 4. ; pour une comparaison voir Monok 2019.

${ }^{8}$ Koltai (szerk.), Magyar udvari. . . 2001; Tüdős 1998; Koltai 2013.
} 
cour des Nádasdy à Sárvár, ${ }^{9}$ ou celle des Batthyány à Németújvár, ${ }^{10}$ relève déjà de cette nouvelle conception - ajoutons tout de suite que le phénomène n'était pas fréquent en Europe occidentale non plus. La résidence des Nádasdy à Pottendorf, ${ }^{11}$ son activité culturelle, la personne et l'entourage du palatin Pál Esterházy, se rapprochent sans aucun doute du modèle occidental. Pourtant, les Esterházy eux-mêmes n'ont pas réussi avant la seconde moitié du XVIII ${ }^{\mathrm{e}}$ siècle à créer un système institutionnel comparable à celui des centres culturels occidentaux majeurs (château, jardin, théâtre, opéra, trésor, musée et bibliothèque), ni à fonder une vie curiale de type occidental (Fraknó, Kismarton, Esterháza). ${ }^{12}$ Ils y seraient parvenus beaucoup plus tôt si la condamnation de la famille Nádasdy en 1671 n'avait brutalement interrompu leur histoire.

La définition structurelle de la cour et le soutien aux différentes institutions dépendaient, comme il va de soi, de la surface financière de chaque famille. Ce n'est pas un hasard si les Nádasdy, ayant réuni le patrimoine des Kanizsai à leurs propres ressources financières, ont pu jouer un rôle pionnier dans la création du système institutionnel de la culture hongroise du XVI siècle. ${ }^{13}$ Les Pálffy, les Thurzó, les Mikulich de Croatie, les Istvánffy et les Zrínyi ont suivi l'exemple des Nádasdy. Certes, par rapport aux familles de Hongrie orientale, les aristocrates proches de Vienne (ou du moins établis dans la partie occidentale du pays) avaient plus de chances de visiter et étudier les cours seigneuriales, princières ou royales européennes. Il faut pourtant s'interdire de tirer des conclusions hâtives portant sur la supposée arriération des cours transylvaines, puisque la plupart des pérégrinations aristocratiques au tournant des $\mathrm{XVI}^{\mathrm{e}}$ et $\mathrm{XVII}^{\mathrm{e}}$ siècles sont le fait de familles transylvaines, notamment les Bethlen et les Kornis. ${ }^{14}$ Notons que seuls quelques aristocrates de la Hongrie royale ont eux aussi effectué un "Grand Tour » (il ne faut pas confondre ce phénomène avec la peregrinatio academica) au XVII ${ }^{\mathrm{e}}$ siècle : Ádám Batthyány et ses fils, István Nádasdy ou Sigismund Széchenyi. ${ }^{15}$

La Transylvanie ne faisant pas partie de l'Empire des Habsbourg, le nombre de Transylvains ayant visité la cour de Vienne (voire y ayant vécu durablement) est limité. Les sources archivistiques portant sur la culture des cours transylvaines sont très rares jusqu'au milieu du XVII ${ }^{\mathrm{e}}$ siècle : ce que l'on en sait provient surtout de sources narratives. ${ }^{16}$ La prédominance de la cour princière et la supériorité économique de la famille princière constituaient un handicap pour l'aristocratie transylvaine, laquelle pouvait néanmoins bénéficier de l'exemple culturel fourni par le prince. Lorsque l'on compare les cours aristocratiques de la Hongrie royale à celles de Transylvanie, nous devons nous rappeler que les cours aristocratiques transylvaines (majoritairement protestantes) étaient chargées, malgré leur moindre puissance économique, de procurer à leur entourage un accès aux

\footnotetext{
99̈̈ptei (szerk.), Nádasdy Tamás. . . 1998; Őze (kiad.), 500 magyar levél. . 1996.

${ }^{10}$ Koppány 1984; Koppány 1990; Koppány 2001; Koltai, KKK IV, 2002; Koppány 2006; Koltai 2008; Koltai 2012.

${ }^{11}$ Viskolcz, KKK VIII, 2013.

${ }^{12}$ Perschy (red.), Die Fürsten Esterházy... 1995; Fatsar 2008; Görtler-Kropf (szerk.), Die Familie Esterházy ... 2009; Körner 2011; - Monok-Zvara 2020.

${ }^{13}$ Klaniczay T. 1985d; Klaniczay T. 1991.

${ }^{14}$ Vass 1912; Binder (kiad.), Utazások. . 1976, 53-74.; Kovács S. I. 1988, 93-200.; Horn 2009, 232-248.; Balogh-Horn 2008 - Lukinich 1911; Lukinich 1926; Monok 1990; Monok 1990a.

${ }^{15}$ Batthyány : Szelestei Nagy (kiad.), Batthyány. . . 1988. - Nádasdy : Toma 2005.; Viskolcz 2011. - Széchenyi : Ötvös P. (kiad.), Széchenyi Zsigmond... 1988.

${ }^{16}$ Fehér (kiad.), Teleki Mihály. . 2007; Tüdős 2006-2008; Tüdős 2009.
} 
livres (et à la culture que les livres représentent). Les cours aristocratiques transylvaines ont conservé cette fonction jusqu'à la fin du XVIII ${ }^{\mathrm{e}}$ siècle (voire, dans certains cas, jusqu'au début du XIX ${ }^{\mathrm{e}}{ }^{17}$

Le premier élément du régime institutionnel de la cour est l'éducation. Dans ce domaine, les aristocrates faisaient appel à des précepteurs, notamment à des représentants de l'Église à laquelle la famille appartenait (prêtres, pasteurs, moines, etc.). ${ }^{18}$ Cela n'impliquait nullement que ladite famille retirait son soutien aux écoles paroissiales présentes sur ses domaines : sans le soutien des nobles, les communautés rurales ne disposaient pas des moyens nécessaires pour mettre en place une éducation élémentaire. Autour de l'éducation fondamentale, certains éléments informels et pratiques étaient enseignés. Les jeunes gens devaient notamment se familiariser avec l'économie, avec les règles de la participation à la politique locale, régionale, éventuellement nationale (dans quelques cas très rares, internationale) et avec la manière d'établir un réseau de relations (en termes modernes : l'acquisition d'un capital de relations). Ils devaient également s'initier à la science militaire, aux coutumes des peuples voisins (surtout les Autrichiens, les Allemands et les Turcs), ainsi qu'aux règles du comportement civilisé (repas, hygiène personnelle, courtoisie, danse, etc.). Les dames de la cour s'appropriaient - certes, selon des modèles différents - des connaissances presque identiques à celles des hommes. La phase suivante de l'éducation prenait éventuellement la forme d'un voyage d'études, lequel représentait une occasion exceptionnelle pour faire un choix personnel de livres. ${ }^{19}$

La question qui nous préoccupe ici en priorité est celle d'identifier la quantité, les sources, la nature et l'usage des livres au sein du processus de formation. On doit de prime abord exclure l'hypothèse selon laquelle la noblesse de Hongrie aurait déterminé un modèle d'éducation applicable aux générations à venir et à leur entourage immédiat conformément aux théories occidentales portant sur l'éducation aristocratique. Dans les catalogues de livres, on ne rencontre guère les ouvrages de Jean-Antoine de Baï, de François de la Noue ou d'Antoine de Pluvinel, ouvrages qui ont exercé une influence décisive sur le programme pédagogique d'écoles nobiliaires comme l'Académie d'équitation d'Angers, ou l'Académie des exercices de Sedan. Ces manuels ont été consultés par Richelieu et par les jésuites lorsqu'ils ont fondé l'Académie Royale de Paris ou le Collège Royale à la Flèche. Les aristocrates hongrois ne connaissaient pas non plus les conceptions pédagogiques proposées par les écoles nobiliaires septentrionales (allemandes et danoises). D'ailleurs, les premières - Heidelberg : Adelschule (1593), Tübingen : Collegium illustre (1594), Kassel : Mauritianum (1596), Sorö : Ritterakademie (1623) - eurent recours aux théories pédagogiques françaises. Un certain Jakob Rathgeb a traduit les livres de François de la Noue et l'Academia Gallica de Pierre de La Primaudaye (livre de chevet de Maurice, prince-électeur de Hesse) en allemand. Les deux ouvrages en langue allemande, maintes fois réédités, de Georg Engelhardt von Löhneysen (Della Cavalleria et Aulico Politica) ne sont en vérité que des compilations savantes des travaux de La Noue. Avant de fonder l'Adelschule de Heidelberg, Johann Casimir n'a pas manqué de demander l'avis personnel de La Noue. Le XVIII ${ }^{\mathrm{e}}$ siècle a vu la fondation de multiples Ritterakademie ou Kriegsakademie en pays germanique. ${ }^{20}$ En Italie, les enseignements dispensés par les écoles équestres furent élargis aux quelques disciplines nécessaires pour la formation de la noblesse. La

\footnotetext{
${ }^{17}$ Péter K. 1986; Köpeczi (gen. ed.), History of Transylvania, 1994.

${ }^{18}$ Várkonyi Á. (szerk.), Magyar reneszánsz. . 1987; Fazekas 2001; Etényi-Horn (szerk.), Idövel paloták. .., 2005.

${ }^{19}$ Zimányi 1998; Koltai (szerk.), Magyar udvari. . [de 12001; Koltai 2013. Cf. Monok 2010.

${ }^{20}$ Conrads 1982.
} 
première Accademia Reale a ouvert ses portes en 1678, à Turin, avec un programme d'enseignement calqué sur celui des écoles françaises. Il faut enfin souligner qu'en dehors des jésuites, les bénédictins ont eux aussi établi quelques écoles réservées aux fils de la noblesse (Ettal, Kremsmünster, Saar en Moravie). Les frères pieux (piétistes) ont fait de même à Varsovie.

Or la noblesse de Hongrie ignorait tout de cette littérature théorique, dont on ne retrouve ni les auteurs ni les titres dans ses bibliothèques. Par contre, à travers la lecture de quelques ouvrages contemporains de philosophie morale et politique, certaines personnalités ont acquis des connaissances portant sur la formation de la jeunesse. Catarinus Dulcis a dirigé, autour de 1602, la première réforme du Mauritianum de Kassel, devenu en 1618 le Collegium Mauritianum Adelphinum. Jouissant en Hongrie d'une popularité comparable à celle de Dulcis, Christoph Besold insistait sur la nécessité de la collaboration entre l'université de Tübingen et l'école nobiliaire. Cela veut dire qu'en Hongrie l'idée de res publica emendenda se diffusait par le biais d'ouvrages de philosophie morale et politique et que la noblesse du pays a pu rencontrer dans ces titres l'idée d'educatio publica selon laquelle elle ne devait pas être éduquée séparément : les jeunes appartenant à cette classe sociale devaient étudier avec les élèves provenant d'autres horizons. Cette voie allait aussi conduire à la reconnaissance de l'utilité de la bibliotheca publica.

Certes, ces idées figurent chez Sénèque et Pétrarque. Parmi leurs partisans les plus actifs, évoquons Guilhelmus Peraldus, auteur très lu dans la Hongrie des $\mathrm{XVI}^{\mathrm{e}}$ et XVII ${ }^{\mathrm{e}}$ siècles. ${ }^{21} \mathrm{Ce}$ théologien - qui a commencé sa carrière comme frère dominicain avant de devenir évêque de Lyon - consacre au sujet et à la De superbia librorum le sixième chapitre de sa Summa virtutum ac vitiorum, chapitre dans lequel il renvoie fréquemment à saint Jérôme. On peut retrouver les mêmes réflexions dans les ouvrages de théorie politique du XVI ${ }^{\mathrm{e}}$ siècle, qui précisent qu'il s'agit là d'une problématique digne de l'attention des princes et des aristocrates. Les ouvrages composés au milieu du siècle n'hésitaient pas à distinguer la nobilitas generis et la nobilitas literata, ${ }^{22}$ et ainsi à signaler aux aristocrates que pour servir la res publica il ne suffit pas de se former soi-même par de vastes lectures : il faut également ouvrir les portes de l'érudition à tous les membres de la communauté politique. ${ }^{23}$ Christoph Besold leur proposait par conséquent de participer activement à la vie de la publica institutio et de s'éduquer eux-mêmes par la voie de la publica disciplina. ${ }^{24}$

${ }^{21}$ «Vitiosum est ubique quod nimium est », Seneca, De tranquillitate animi 9,4-7.; « distingit librorum multitudo », Seneca, Epistola ad Lucilium 1,2. - Franciscus Petrarcha, De remediis utriusque fortunae libri II, Lugduni, Carolus Pesnot, 1585, 177-184. - Peraldus : Antverpiae, off. Plantiniana, 1567, Tractatus 6, De superbia librorum.

${ }^{22} \mathrm{Cf}$. Laurentius Hunfredus (Humphrey), Optimates sive de nobilitate, Basileae, Johannes Oporinus, 1559, 326. (« se armis, non literis natos predicant /sc. nobiles/ »)

${ }^{23}$ Cf. par ex.: Kumaniecki, ed., Modrevius, 1953, 56-57.: « Nulla est igitur compediosor ad sapientiam perveniendi via, quam lectio librorum tum sacrorum, tum etiam a viris eruditis conscriptorum. »

${ }^{24}$ Christoph Besoldus, Discursus politici singulares de informatione et coactione. . . Argentorati, sumptibus Lazari Zetzneri, 1626, 16.: « Ego puto publicam disciplinam in sapientia et consensu totius civitatis fundatam, firmiorem quidem constantiam habere, quam ab unius quae judicio pendet » - 27.: « Juvat et habere publicas bibliothecas... nulliusque privati... »; un programme similaire de Cyriacus Spangenberg, Ander Theil des Adelspiegels, Schmalkalden, Michael Schmück, 1594, ff. 75v-77v.: Von Bibliothecken oder Librareyen: « Neben wolbestelleten Predigstülen vnd rechtschaffen angerichten Schulen sind gute Bibliotheken nicht allein ein schönes lustiges Kleinodt, sondern auch ein notwendig stück, daran gar viel gelegen vnd solchs auch nicht wenig zu beförderung vnd erhaltung warer Religion vnd guter Künste nützlich vnd dienstlich ist. Denn alle Pfarrherrn, Professores vnd Schulmeister des Vermögens nicht sind das sie alle Patres, Historicos, vnd andere gute Autores für sich selbst zeugen möchten, deren sie aber doch nicht allwege allerding entraten können. » Cf. Müller 1984. 
La source principale à laquelle ils puisaient les connaissances pédagogiques et politiques demeurait néanmoins les livres d'histoire. Il est très difficile de faire le départ entre la philosophie morale, les miroirs princiers et les chapitres méditatifs des livres d'histoire. Nous devons donc leur accorder une attention particulière. ${ }^{25}$

Pas plus que dans le domaine de l'éducation, les aristocrates de Hongrie n'ont puisé leurs connaissances économiques dans les livres. Cela concerne également les intendants (régisseurs), même si l'excellence d'un certain nombre de serviteurs (György Perneszith auprès des Nádasdy, ${ }^{26}$ Tamás Debreczeni auprès de Rákóczi, ${ }^{27}$ ou Péter Borbereki Alvinczi, régisseur des Apaffi $)^{28}$ paraît témoigner de la naissance d'une intelligentsia économique. L'on sait bien qu'en France, Colbert fit écrire un ouvrage sur l'économie à l'usage de la noblesse, mais, en Hongrie, on ne retrouve aujourd'hui aucun exemplaire, ni de la Méthode pour bien dresser toutes sortes de comptes de Claude Irson, ${ }^{29}$ ni du Traité de la noblesse de Gilles-André de La Roque. ${ }^{30}$ Pour autant, les ouvrages de théorie politique dont disposaient les nobles de Hongrie renfermaient quelques connaissances générales que l'on qualifierait volontiers d'économiques. ${ }^{31}$

Une famille nobiliaire moyenne possédait quelques livres. Chaque membre de la maisonnée disposait de ses livres à usage personnel : livres scolaires, catéchèses, livres de piété et enfin quelques lectures reflétant le goût personnel de son propriétaire. Pratiquement toutes les familles aristocratiques avaient en outre une bibliothèque, dans la plupart des cas dépourvue de catalogue ou de registre. Les renseignements dont nous disposons à leur sujet proviennent de feuilles d'achat, de factures, de notes de régisseurs ou de registres successoraux. Nombreuses sont les bibliothèques dont quelques pièces subsistent jusqu'à nos jours, par contre, très rares sont les familles des $\mathrm{XVI}^{\mathrm{e}}$ - XVII ${ }^{\mathrm{e}}$ siècle, qui ont légué à la postérité non seulement des catalogues contemporains, mais aussi des livres que les chercheurs soient en mesure de consulter (signalons Miklós Zrínyi, le palatin Pál Esterházy et, dans une moindre mesure, Ferenc Nádasdy, juge royal). ${ }^{32}$

La bibliothèque curiale était une collection pour l'usage commun, à laquelle tous les membres de la cour avaient accès. Prenons l'exemple d'une bibliothèque dont la création fut motivée par la bibliophilie de son propriétaire (la bibliothèque Esterházy à Kismarton) : les ouvrages consacrés aux techniques de la construction des fontaines - acquis, sans doute, sur la proposition de l'artiste-architecte - purent être utilisés par l'ingénieur responsable de l'exécution. ${ }^{33}$ Dans la période qui nous intéresse, nous ne connaissons - en dehors de la collection Esterházy mentionnée plus haut et de la collection Nádasdy de Pottendorf - aucune bibliothèque qui ne soit fonctionnelle et censée satisfaire les besoins de la cour entière et de son milieu environnant.

\footnotetext{
${ }^{25}$ Neddermeyer 1998; Müller 1998; Ranum 1998; Kruse-Paravicini (éd.), Höfe und Hofordnungen. . 1999.

${ }^{26}$ Kumorovitz-Kállai (kiad.), Kultúrtörténeti. . 1959.

${ }^{27}$ Makkai, sajtó alá rend., I. Rákóczi... 1954.

${ }^{28}$ Szilágyi S. (kiad.), Alvinczi... 1870.

${ }^{29}$ Paris, Jean Cusson, 1678.

${ }^{30}$ Paris, Etienne Michallet, 1678.

${ }^{31}$ Ribard 2007.

${ }^{32}$ Monok 1994.

${ }^{33}$ Par ex. l'œuvre d'Antoine Joseph Dézalier d'Argenville (La Théorie et la Pratique du Jardinage) était diffusée en Hongrie. Cf. Fatsar 2008.
} 
Voyons maintenant le procédé d'acquisition des livres. Les aristocrates et les nobles ne pouvaient s'adresser à aucune librairie permanente, puisqu'il n'en existait aucune en Hongrie (jusqu'à la fin du XVIII ${ }^{\mathrm{e}}$ siècle). L'offre commerciale des ateliers de reliure était assez modeste : on ne pouvait s'y procurer, en règle générale, que des ouvrages scolaires et des ouvrages de piété. La recherche a certes identifié quelques libraires de Haute-Hongrie et de Transylvanie, mais ils s'adressaient surtout au public bourgeois $;{ }^{34}$ les agents des éditeurs étrangers (surtout viennois, d'Allemagne du Sud et d'Italie du Nord), s'ils ont essayé d'établir des contacts réguliers avec les familles aristocratiques hongroises, se sont efforcés de vendre uniquement les livres publiés par leur maison-mère. Il convient d'accorder une attention particulière aux rapports liant la famille Batthyány et le huguenot parisien, réfugié à Francfort, André Wechel, ainsi que ses gendres (Jean Marne, Jean Aubry) et leurs descendants. ${ }^{35}$ Soulignons également un fait intéressant : le palatin Ferenc Nádasdy avait l'intention d'ouvrir une librairie à Vienne en collaboration avec la famille Moretus d'Anvers. ${ }^{36}$

Les alumni poursuivant leurs études aux frais des familles aristocratiques ont enrichi avec un certain succès les bibliothèques familiales : leurs goûts personnels et leurs orientations intellectuelles ont laissé une trace indélébile dans la bibliothèque de leur patron. Le grand seigneur hongrois disposait par ailleurs de diverses possibilités pour choisir des livres correspondant à son goût. L'occasion la plus évidente se présentait lors des voyages : en visitant une grande ville européenne célèbre pour ses librairies, il était possible de consulter personnellement des ouvrages dont on n'avait aucune connaissance préalable. Nous pourrions citer ici plusieurs cas concrets, dont les plus connus concernent les voyages européens de Boldizsár (Balthasar) Batthyány, Miklós Zrínyi et Ferenc Nádasdy, voyages qui transformèrent de fond en comble le goût du collectionneur. Une forme très spécifique du voyage était celle par laquelle un grandseigneur, officier de l'armée impériale, participait aux campagnes militaires européennes et y trouvait l'occasion de visiter les librairies de quelque grande ville occidentale (voir l'exemple d'Ádám Czobor et de György Csáky). ${ }^{37} \mathrm{Il}$ arrivait aux aristocrates - et c'était une belle occasion d'acquérir des livres selon son goût - d'acheter un patrimoine entier. Nous ne disposons que de preuves indirectes attestant l'existence de telles transactions, qui avaient le plus souvent pour objectif d'accorder un soutien financier à une veuve illettrée. C'est ainsi que les livres d'István Jóna sont entrés dans la bibliothèque familiale des Zrínyi, ${ }^{38}$ mais on peut également citer le rachat de la bibliothèque de Máté Csanaki par les Rákóczi. ${ }^{39}$ Les livres en question, pour lesquels nous disposons d'un catalogue en registre, sont précisément ceux qui se trouvaient en double à Sárospatak : c'est la raison pour laquelle ils furent envoyés en Transylvanie, soit dans la bibliothèque princière, soit dans la bibliothèque scolaire de Gyulafehérvár. Par contre, lors de l'achat d'une succession, les grands-seigneurs ne pratiquaient pas de sélection: ils prenaient l'ensemble.

\footnotetext{
${ }^{34}$ Monok 2004; Monok 2007; Monok 2012.

${ }^{35}$ Evans 1975; Ecsedy 1999; Bobory 2009.

${ }^{36}$ Viskolcz 2011.

${ }^{37}$ Ötvös P. 1980.

${ }^{38}$ Hausner-Klaniczay-Kovács S. I.-Monok-Orlovszky (eds.), Bibliotheca Zriniana, 1991.

${ }^{39}$ Monok 1983; Monok, KKK I, 1996, 7-29.
} 
Certes, les registres publicitaires (Verlagskatalog) que les libraires adressaient aux cours seigneuriales ne permettent pas une étude approfondie du contenu des livres eux-mêmes, toutefois, il apparaît au moins qu'en déterminant la composition thématique de sa collection, chaque seigneur a pu faire entendre ses préférences. Pour l'historien, le principal inconvénient de l'acquisition de livres par la voie d'un registre publicitaire (Verlagskatalog) réside dans le fait que l'acheteur était exposé aux aléas des intérêts commerciaux du libraire : les agents ne proposaient aux clients potentiels que les livres publiés par la maison d'édition qui les payait. Plus utiles sont par conséquent les catalogues des foires du livre (Francfort-surle-Main, Leipzig), diffusés de plus en plus largement à partir de la fin du XVI siècle. Nous conservons un exemplaire envoyé à Boldizsár Batthyány par Jean Aubry, ${ }^{40}$ gendre d'André Wechel, l'imprimeur huguenot réfugié de Paris à Francfort. Les documents relatant l'histoire des rapports liant Balthasar Moretus et Ferenc Nádasdy, exécuté en 1671, ont été mis à jour par Noémi Viskolcz, qui les a présentés dans son étude consacrée à Nádasdy. Le comte disposait d'un exemplaire du catalogue de l'éditeur anversois, qu'il a prêté à György Lippay, archevêque d'Esztergom. ${ }^{41}$ On sait que Pál Ráday, au début du XVIII ${ }^{\mathrm{e}}$ siècle, a sélectionné des livres en vue d'une acquisition dans le catalogue de la foire de Leipzig. ${ }^{42}$ Bien sûr, d'autres grands-seigneurs pouvaient aussi connaître cette manière de se renseigner sur les livres.

Néanmoins, la situation la plus fréquente était l'achat par un intendant, à l'occasion d'un déplacement à l'étranger, soit des livres que la famille avait demandés, soit de ceux qu'il considérait lui-même comme dignes d'intérêt. Dans la plupart des cas, les mandataires ne désignaient pas explicitement les livres visés : par exemple, il pouvaient souhaiter, d'une manière générale, des livres d'histoire, ou des livres consacrés aux territoires récemment découverts, ou encore des albums illustrés présentant les empereurs, etc. La personne exécutant l'achat disposait donc d'une marge de manœuvre assez considérable dans le choix de livres conformes aux exigences de son mandataire. Plusieurs documents des $\mathrm{XVI}^{\mathrm{e}}$ et $\mathrm{XVII}^{\mathrm{e}}$ siècles attestent de la relative fréquence de ce phénomène : voir les activités de György Perneszith, ${ }^{43}$ intendant au service des Nádasdy, ou les lettres de la famille Csányi. ${ }^{44}$ On a pu observer l'existence de cas similaires à la cour des Zrínyi. ${ }^{45}$ Certes, les agents et les intendants ne franchissaient pas nécessairement de grandes distances pour se procurer des livres. Ceux de Hongrie occidentale et de la partie occidentale de la Haute-Hongrie avaient pour destination Vienne et Graz, les habitants de la Hongrie septentrionale se rendaient à Cracovie, tandis que les agents des grands-seigneurs de Croatie préféraient Venise. Toutes ces villes étant catholiques, les exigences d'ordre religieux, théologique et ecclésiastique des seigneurs protestants ne pouvaient être satisfaites de cette manière. Par conséquent, ils prirent l'habitude de confier la tâche d'acquérir des livres aux jeunes lettrés qui poursuivaient leurs études en Europe occidentale grâce au soutien financier de ces

\footnotetext{
${ }^{40}$ Evans 1975; Monok 2005; Monok 2006; Le catalogue de Wechel: Monok-Ötvös P.-Zvara 2004, Nr. 116.

${ }^{41}$ Viskolcz 2011.

${ }^{42}$ Bajáki-Bujdosó-Monok-Viskolcz-Zvara, Adattár 13/4, 2009, 189-297; Borvölgyi, KKK VII, 2004.

${ }^{43}$ Kumorovitz-Kállai (kiad.), Kultúrtörténeti. . 1959.

${ }^{44}$ Öze (kiad.), 500 magyar levél. .. 1996.

${ }^{45}$ Herner-Monok, (szerk.)., Adattár 11, 1983, 553-554.
} 
mêmes seigneurs. Beaucoup d'annotations de journaux et d'albums, ainsi qu'une multitude de lettres, attestent des achats exécutés par ce biais. ${ }^{46}$ Les envoyés accomplissant une mission diplomatique se chargeaient également de la tâche d'acheter quelques livres pour le compte de leur mandataire. Enfin, les seigneurs ont souvent demandé aux colporteurs qui se déplaçaient en Europe d'acquérir tel ou tel volume souhaité. D'ailleurs, les étudiants séjournant à l'étranger n'ont pas hésité à envoyer à leurs mandataires les livres obtenus par les soins de ces colporteurs.

L'entretien des institutions liées à la cour (imprimerie, bibliothèque, école, jardin) et l'organisation générale de leurs activités respectives, de même que le mécénat figuraient parmi les obligations des familles de la haute noblesse. Notons en passant qu'en agissant en mécènes, les aristocrates ont contribué à l'enrichissement de leurs propres bibliothèques : on peut légitimement supposer que les auteurs ou imprimeurs soutenus par un aristocrate lui firent don - par obligation morale, mais aussi par intérêt - d'au moins un exemplaire des ouvrages publiés. C'est la raison pour laquelle, en recensant le corpus des bibliothèques aristocratiques, nous relevons systématiquement la mention des ouvrages dédiés aux membres de la famille. Enfin, les livres publiés par les imprimeurs itinérants ne doivent pas être négligés lorsque l'on s'efforce de dessiner l'horizon culturel de tel ou tel grand-seigneur.

Les familles aristocratiques ne se sont pas contentées de fonder des écoles attachées à leur cour : elles ont aussi contribué à l'entretien des écoles existant sur leurs domaines (souvent, le bâtiment lui-même appartenait à la famille). Les grands-seigneurs aidèrent les plus doués des jeunes gens à poursuivre des études secondaires dans le pays et des études supérieures à l'étranger. Ils payaient les instituteurs et les professeurs et ils ne manquèrent pas de développer les bibliothèques scolaires, au moyen de dons ou d'achats directs ou en leur léguant par voie testamentaire les livres nécessaires. Prenons l'exemple d'Imre Forgách qui, en 1588, fit don à l'école luthérienne de Trencsén ${ }^{47}$ de tous les exemplaires extraits de sa propre bibliothèque qu'il pensait pouvoir être utiles.

Boldizsár Batthyány, quant à lui, a soutenu l'école de Németújvár d'une autre manière. Si l'on en croit le témoignage des livres eux-mêmes, aujourd'hui conservés, l'aristocrate a transmis à l'établissement des livres provenant de la maison conventuelle des augustiniens, qui ont été régulièrement utilisés par les instituteurs de l'école, ainsi que par les pasteurs du village et du château ${ }^{48} \mathrm{Par}$ contre, dans la seconde moitié du XVI ${ }^{\mathrm{e}}$ siècle, une partie importante des ouvrages a été utilisée comme matériau de reliure (Gedeon Borsa a donc raison quand il évoque la fameuse « reliure de Németújvár »). ${ }^{49}$ Du reste, Boldizsár ne se contenta pas d'avoir transmis à l'école les livres des moines : il renonça également à ceux de ses propres livres, surtout théologiques, auxquels il était le moins attaché (sur lesquels, tout de même, il avait apposé son ex-libris et parfois même écrit quelques notes). Boldizsár et son fils, Ferenc, accueillaient volontiers à leur cour des érudits (enseignants ou pasteurs) fuyant la persécution et qui, par gratitude, leur ont transmis leurs livres. ${ }^{50}$ Par la suite, on peut citer de multiples exemples

\footnotetext{
${ }^{46}$ Hoffmann, szerk., Peregrinuslevelek. . Adattár 6, 1980; inventaires du livre de Sámuel Kaposi dans : Monok-Németh (Viskolcz)-Varga A., Adattár 16/3, 1994, 223-264.; Bíró Gy.-Monok-Verók, Adattár 16/5, 2018, 40-49.

${ }^{47}$ Farkas G. F.-Katona-Latzkovits-Varga A., Adattár 13/2, 1992, 3-9.

${ }^{48}$ Monok-Ötvös P.-Zvara 2004.

${ }^{49}$ Borsa 1972. Cf. Gilányi 2019.

${ }^{50}$ Monok 2004; Monok 2004a.
} 
analogues : Ádám Batthyány, quant à lui, après avoir supprimé l'école protestante, introduisit dans ses domaines les moines franciscains et soutint généreusement l'éducation catholique de ses sujets. ${ }^{51}$ Pál Pálffy, à Malacka, ${ }^{52}$ et les Rákóczi à Sárospatak ${ }^{53}$ ont agi de la même manière.

La question se pose aussitôt : les livres que les grands-seigneurs confièrent aux écoles et aux maisons conventuelles les plus diverses relèvent-ils de la culture aristocratique ? Les aristocrates avaient sans doute une certaine culture livresque liée à la formation scolaire. Ils étaient aussi familiers, en fonction de leur appartenance confessionnelle, des livres de piété quotidienne, souvent des volumes de petit format. Si on ne peut pas affirmer avec certitude qu'ils ont effectivement lu les prédications figurant dans les collections de sermons publiées grâce à leur soutien financier, ils les ont probablement entendues à l'occasion du service religieux ou de conversations personnelles avec les prêtres ou pasteurs. Les auteurs antiques - grâce aux livres scolaires et aux éditions de proverbia acquises à l'étranger - leur étaient également familiers. Les lectures historiques se trouvaient au centre de leur intérêt, et ils avaient aussi des connaissances (certes, le plus souvent assez superficielles) au sujet des auteurs théologiques les plus importants : ils savaient donc ce qu'ils avaient donné aux écoles. On sait que pour étudier la culture « livresque » des couches sociales les plus basses, il faut se garder de négliger la transmission orale des éléments d'érudition. ${ }^{54}$ Finalement, cette précaution méthodologique est encore plus valide s'agissant de la culture des aristocrates, qui avaient toujours la possibilité de compléter leurs connaissances de base en échangeant avec des « experts » (enseignants, pasteurs, hommes de science, d'autres aristocrates, etc.).

L'évaluation des connaissances culturelles et scientifiques de tel ou tel grand seigneur nous informe remarquablement sur l'horizon des membres de la cour dans son ensemble, dont une partie importante s'appuyait sur la culture livresque. Citons l'exemple de ce voyageur en provenance de Bruges, qui rapporte que lors de son séjour dans la maison des Batthyány à Presbourg (1658), l'un des fils d'Adam (Kristóf ou Pál), présenta les traditions et la culture hongroises en jouant du violon, puis en dansant à la manière hongroise avec sa mère. Le jeune aristocrate témoignait ainsi de certains aspects de sa culture : il savait que l'étranger, originaire des Pays-Bas, pouvait s'intéresser aux spécificités de la tradition hongroise et il savait aussi que là où l'étranger était né, rien n'était comme en Hongrie. ${ }^{55}$ Certes, on ne peut pas constater avec précision la nature et la quantité des connaissances dont le jeune aristocrate disposait au sujet de Bruges et de ses environs. Il en avait sans doute discuté avec l'invité, ou préalablement à la visite, avec les personnes de son entourage qui avaient pu lire quelque chose sur le sujet, ou en avoir une expérience directe.

Voilà pourquoi je suis convaincu de l'utilité de prendre en considération les livres et les lectures des différents agents et familiers de la cour (en majorité des nobles, eux aussi). Comme les subordonnés avaient accès à la bibliothèque de leur maître, celui-ci pouvait être, en contrepartie, attentif aux connaissances dont ils disposaient. La culture de György Perneszith, conforme à l'esprit du temps, témoigne de la modernité et de l'ouverture de la cour des Nádasdy à Sárvár : on peut tirer les mêmes conclusions des connaissances économiques de Tamás

\footnotetext{
${ }^{51}$ Koltai, KKK IV, 2002, 120-147.

${ }^{52}$ Hausner 2009.

${ }^{53}$ Monok, KKK I, 1996; Várkonyi Á. 2008.

${ }^{54}$ Kristóf 1995; Kristóf 2008.

${ }^{55}$ Monok 1989; Monok 1989a.
} 
Debreceni et Péter Alvinczi de Borberek au sujet de l'état d'esprit à la cour des Rákóczi et des Apaffi. Une attention toute particulière doit être portée aux titres faisant partie de la bibliothèque du pasteur ou du prêtre curial (de ce point de vue, on s'intéressera également aux éventuelles lacunes). L'érudition de la famille Beythe (pasteurs protestants) a enrichi non seulement les Bánffy, mais aussi les Batthyány. ${ }^{56}$ Il n'était d'ailleurs pas rare qu'un ecclésiastique léguât ses livres au grand-seigneur qui l'avait soutenu : c'est ce que montre l'exemple de Francesco Orsolini dont la collection est passée à Pál Esterházy). ${ }^{57}$

Un autre domaine concerne les livres d'usage commun disponibles à la cour. Leur présence atteste de la forte volonté d'acquisition collective de connaissances par le biais de la conversation érudite, et l'on ne peut guère imaginer que le grand-seigneur ait été absent de ces échanges ${ }^{58} \mathrm{Le}$ meilleur exemple permettant d'illustrer le phénomène nous est donné par la cour des Batthyány à Németújvár, en l'occurrence par la personne de Boldizsár Batthyány. Dans cette cour, les membres de la famille Beythe créèrent une sorte d'atelier théologique où chacun mettait ses livres en commun. En même temps, Boldizsár faisait partie du cercle humaniste de Presbourg, tout comme, d'ailleurs, le botaniste attaché à sa cour, Charles de L'Écluse. ${ }^{59}$ Certes, la plupart de ces cercles fonctionnaient au sein de cours de prélats (nous traiterons de cette question dans le cadre d'une autre étude), mais on peut mentionner quelques familles de grand-seigneurs laïques - en dehors des Batthyány - qui ont entretenu cette forme de sociabilité : en Transylvanie, l'entourage de Zsigmond Kornis, ${ }^{60}$ ainsi que les Listi ${ }^{61}$ (qui avaient hérité d'excellents ouvrages humanistes venant de leur père, Miklós Oláh).

$\mathrm{Si}$, dans la plupart des recensements de livres dont nous disposons, les exemplaires du chef de famille ne sont pas distingués de ceux des autres membres de la famille, ce n'est pourtant pas toujours le cas. La recherche peut parfois repérer les lectures qui correspondent aux différentes phases de vie. Puisque l'on dispose de connaissances relativement étendues au sujet des livres scolaires, on peut établir une comparaison entre les études que poursuivaient les enfants Pálffy (aristocrates de Haute-Hongrie), ${ }^{62}$ ceux de Miklós Bethlen, ${ }^{63}$ ou de la famille de Zsigmond Rétyi, membre de la petite noblesse transylvaine. ${ }^{64}$ En principe, on ne devrait pas observer trop d'écart, puisque le régime scolaire de l'époque n'autorisait pas de différences majeures entre les écoles de même niveau. Mais, dans les familles qui pouvaient se permettre d'employer un précepteur pour favoriser la réussite du cursus scolaire (par exemple les Pálffy), les jeunes gens avaient la possibilité de consulter les textes des « auteurs scolaires » non seulement en éditions scolaires (pro usu delfini), mais aussi dans les collections d'œuvres complètes. Ils pouvaient en outre compléter leurs connaissances par quelques éléments «non obligatoires».

\footnotetext{
${ }^{56}$ Monok 2005; Monok 2006.

${ }^{57}$ Grüll-Keveházi-Kokas-Monok-Ötvös P.-Prickler (éd.), Adattár 18/2, 1996, 189-192.

${ }^{58}$ Monok 2007a; Monok 2012.

${ }^{59}$ Pajkossy 1983; Boross 2007.

${ }^{60}$ Klaniczay 1985; Horn 2009.

${ }^{61}$ Hausner-Klaniczay-Kovács S. I.-Monok-Orlovszky (hrsg), Bibliotheca Zriniana, 1991, 302 (Nr. 352 ); cf. Zvara 2008.

${ }^{62}$ Bajáki-Bujdosó-Monok-Viskolcz-Zvara, Adattár 13/4, 2009, 27-28.

${ }^{63}$ Monok-Németh (Viskolcz)-Varga A., Adattár 16/3, 1994, 14-15.

${ }^{64}$ Ursuţiu (kiad.), Rétyi Péter... 1983, 39, 56; Monok-Németh (Viskolcz)-Tonk, Adattár 16/2, 1991, 121.
} 
Si les femmes lisaient aussi, il faut ici apporter quelques nuances : elles bénéficiaient en outre d'une éducation, au sens plus large, en partie livresque. ${ }^{65}$ On peut par exemple penser aux connaissances sur l'habillement : il existait au XVI ${ }^{\mathrm{e}}$ siècle des livres de mode. ${ }^{66}$ Certes, les premières bibliothèques féminines - des collections que l'épouse du grand-seigneur constituait pour son propre usage - datent du XVIII ${ }^{\mathrm{e}}$ siècle. ${ }^{67} \mathrm{Il}$ faut pourtant poser, au titre d'époques antérieures, la question de la possession de livres par les femmes. On peut par exemple rencontrer des inventaires de livres occasionnés par une transmission de biens par la branche féminine ; on faisait souvent l'inventaire des biens d'une veuve, et une partie importante en était constituée de livres familiaux. Si Borbála Telegdi ${ }^{68}$ ou Borbála Batthyány ${ }^{69}$ ne lisaient sans doute pas les livres qui se trouvaient dans la bibliothèque familiale, les recensements de leurs collections caractérisent ${ }^{70}$ par contre probablement assez bien les lectures de Judit Veér (femme du chancelier Mihály Teleki) ${ }^{71}$ ou d'Anna Bornemisza (femme du prince Mihály I ${ }^{\text {er }}$ Apaffi. ${ }^{72}$

$\mathrm{Au}$ cours des dernières décennies, la recherche portant sur l'histoire des bibliothèques aristocratiques a été associée à l'histoire de la bibliophilie, ${ }^{73}$ mais la première question qui préoccupait les chercheurs a été de savoir dans quelle mesure le propriétaire a lu ou non les livres rassemblés. ${ }^{74}$ De nos jours, l'histoire des bibliothèques est liée à l'étude des collections de raretés, de curiosités, de musées ${ }^{75}$ et à l'histoire du goût. ${ }^{76}$ Les livres entrés dans les cours aristocratiques hongroises ne peuvent tout simplement pas être considérés comme recouvrant les lectures de la famille, ainsi que je l'ai montré tout à l'heure. Voilà pourquoi nous devons procéder très prudemment lorsqu'il s'agit de déterminer quels sont les livres destinés à l'usage personnel de tel ou tel grand-seigneur. Souvent, le chercheur peut se faire une idée avec une relative certitude : par exemple, les factures de livres que nous conservons de la bibliothèque de Boldizsár Batthyány renvoient sans doute aux livres voués à son usage personnel. ${ }^{77}$ Ce n'est pas par hasard si les livres figurant sur ces factures ne rentraient que très rarement dans la bibliothèque de l'école protestante associée à sa cour. De même, les lectures dont les grands-seigneurs font mention dans leurs correspondances ou dans leurs journaux intimes ont une importance particulière pour les chercheurs. ${ }^{78}$

\footnotetext{
${ }^{65}$ Monok 2015; Monok 2016.

${ }^{66}$ Gynaeceum sive Theatrum mulierum ... figuris ... expressos a Iodoco Amano ... Francofurti, Sigmund Feyerabend, 1586.

${ }^{67}$ Deé Nagy 1996.

${ }^{68}$ Bajáki-Bujdosó-Monok-Viskolcz-Zvara, Adattár 13/4, 2009, 32; Monok, KKK I, 1996, 205.

${ }^{69}$ Farkas G. F.-Katona-Latzkovits-Varga A., Adattár 13/2, 1992, 110-113.

${ }^{70}$ cf. Soltész 1995; Sárdi 2004; Pesti 2010; Pesti 2013, 186-236.

${ }^{71}$ Monok-Németh (Viskolcz)-Varga A., Adattár 16/3, 1994, 125-126.

${ }^{72}$ Monok-Németh (Viskolcz)-Varga A., Adattár 16/3, 1994, 71-74.

${ }^{73}$ Par ex. De Benedictis 1998; López-Vidriero-Cátedra 1998.

${ }^{74}$ Raabe 1982; Raabe 1984.

${ }^{75}$ Raffler 2007; Bödeker-Saada (hrsg.), Bibliothek als Archiv... 2007; De Pasquale-Capua, a cura di, Le Biblioteche... 2019.

${ }^{76}$ Tortorelli, a cura di, Bibliothece. . 2002.

${ }^{77}$ Herner-Monok, sajtó alá rend., Adattár 11, 1983, 410-433.; Monok-Ötvös P.-Zvara 2004.

${ }^{78}$ Ötvös P. 1988.
} 
En rapport étroit avec ce qui a été dit précédemment, nous devons souligner le fait que pratiquement tous ceux qui étudient la réception en Hongrie des courants intellectuels de la première modernité n'échappent pas à un certain nombre de préjugés. L'une de ces préventions est assez facile à concevoir : de quelque époque qu'il s'agisse, il est toujours très intéressant d'étudier les ouvrages qui figurent dans les « brèves récapitulations de l'histoire de la philosophie et de la pensée humaine ». Les auteurs les plus illustres, les novateurs et les anticipateurs qui n'étaient pas forcément appréciés par leurs contemporains, mais que la postérité a ensuite classés parmi les plus grands, s'attirent irrésistiblement l'intérêt des chercheurs. Cette attitude - que je qualifierais volontiers de naturelle - a été renforcée par le fait regrettable qu'après la Seconde Guerre mondiale, les thèmes de recherche dits «progressistes » ou du moins « antiféodaux » bénéficièrent, pour des raisons idéologiques évidentes, d’une attention particulière : tout ce qui pouvait être classé dans la case « pré-Lumières » passait très bien. La gamme en était très variée : la logique dialectique de Nicolas de Cues, la Réforme dans son ensemble (et surtout dans son aspect anti-trinitaire), les moments les plus illustres du rationalisme philosophique et du scepticisme scientifique. Toutes les indications et tous les renvois attestant de la présence de tel ou tel auteur « progressiste » furent amplifiés et leur importance systématiquement surestimée dans les analyses.

Notons que la volonté crispée de se conformer aux directions de recherche actuellement à la mode en Europe occidentale ou aux États-Unis peut aussi conduire à certains dysfonctionnements. Certes, dans la plupart des cas, les épigones n'énoncent pas de manière catégorique l'applicabilité sur le corpus entier des sources hongroises de telle ou telle théorie en cours : il s'agit plutôt de chercher des indications susceptibles d'attester la validité générale de ladite théorie. Lorsqu'il rencontre un livre "curieux », le chercheur visant à une certaine notoriété internationale ne manquera pas d'exagérer l'importance de sa découverte et de tirer de la présence d'un tel ouvrage des conclusions hâtives. ${ }^{79}$ Exemple : on peut trouver dans la Hongrie du tournant des $\mathrm{XVI}^{\mathrm{e}}$ et $\mathrm{XVII}^{\mathrm{e}}$ siècles, quelques titres rosicruciens, mais il serait absolument déplacé de parler d'une sorte de Renaissance rosicrucienne dans le pays. L'analyse statistique du corpus prouve de manière évidente qu'un nombre très limité de personnes étaient familiers des ouvrages d'auteurs que l'on considère aujourd'hui comme les pionniers de la pensée philosophique et scientifique ; en revanche, ils ont plutôt trouvé leur inspiration dans les ouvrages, publiés en tirage très élevé, des auteurs de deuxième ou de troisième ordre (le plus souvent des théologiens, professeurs, pasteurs ou prêtres catholiques, calvinistes ou luthériens).

On trouve certes à la cour des Batthyány des ouvrages rosicruciens et des traités weigeliens, mais il ne s'ensuit nullement que le grand-seigneur (ou même son pasteur) savait de quels textes il s'agissait. Même en supposant qu'un pasteur le sût, il était sans doute le seul à pouvoir dire à son employeur, le grand-seigneur, si l'auteur en question était dangereux, hérétique ou dépositaire de la vérité. Il importe donc de se renseigner sur la manière dont tel ou tel livre a d'abord été acquis, afin de minimaliser le risque de surestimer l'importance d'un phénomène isolé ou survenu par hasard. Selon toute probabilité, Ferenc Batthyány ignorait ce qu'était le weigelianisme, puisque les ouvrages de Weigel ont été introduits à la cour et à l'école par Johann Jacob Knaus ${ }^{80}$ après que celui-ci eut été contraint de quitter le Wurtemberg parce que les autorités avaient trouvé suspecte et peu orthodoxe sa façon de penser. En revanche, Boldizsár

\footnotetext{
${ }^{79}$ Szőnyi Gy. E. 1985; Péter K. 1987.

${ }^{80}$ Monok 2003.
} 
Batthyány devait savoir qui était Jean Bodin : on peut légitimement admettre qu'il a lui-même choisi le livre du penseur français en connaissance de cause, comme le fait supposer l'étude du catalogue de ses livres. ${ }^{81}$ Je trouve excessive l'interprétation de Dóra Bobory qui pense pouvoir identifier dans la cour des Batthyány les débuts de la pensée paracelsienne en Hongrie. ${ }^{82}$

L'historien ne doit pas oublier le fait que la lecture et l'étude au sujet des questions débattues par les clercs travaillant sur leur domaine n'étaient sans doute pas l'occupation principale des grands-seigneurs. Certes, on peut toujours trouver des exceptions, mais j'imagine mal György Thurzó - accablé de la charge de palatin et encombré de manière permanente par divers procès familiaux et autres affaires - étudier en profondeur les débats portant sur l'orthodoxie wittenbergienne et sur le philippisme tardif. On ne saurait imaginer que les aristocrates aient attentivement lu tous (ou la majorité) des livres qui se trouvaient dans leur collection. Cette remarque vaut aussi pour les grands-seigneurs particulièrement érudits, comme l'était justement Thurzó. ${ }^{83}$ De ce point de vue, il est très instructif de confronter les études de Mihály Balázs et d'Ildikó Horn sur l'unitarisme et la noblesse unitarienne. ${ }^{84}$

Nous n'avons, hélas, que très rarement la possibilité d'analyser les livres ayant appartenu à plusieurs générations d'une même famille. Néanmoins, lorsque cela est possible, les résultats exigent des interprétations très retenues et prudentes. Quelques questions typiques s'imposent : les transformations affectant le corpus de livres peuvent-elles, par exemple, s'expliquer par une conversion ? Par quel moyen évaluer la largeur ou l'étroitesse d'esprit d'un grand-seigneur ? Deux exemples suffiront ici : le catalogue (fragmentaire) de la bibliothèque des Rákóczi à Sárospatak témoigne d'une collection spectaculairement moderne, ouverte à la fois sur le plan confessionnel et mondain (séculier). Or les témoignages que nous avons de György I ${ }^{\mathrm{er}}$ Rákóczi ou de Zsuzsanna Lórántffy ne confirment pas cette image. L'historienne Katalin Péter attribue à Zsigmond (Sigismond) Rákóczi ${ }^{85}$ - cet érudit, mort jeune, discutait volontiers avec Johannes Amos Comenius - la modernisation de la bibliothèque. Cette hypothèse n'est pas à exclure, mais ce qui est certain, c'est que György Rákóczi, qui devint tuteur des enfants de son frère, Paul, à la mort de ce dernier, fit transporter tous les livres du défunt à Patak. ${ }^{86}$ Comme second exemple, prenons la bibliothèque des Eszterházy à Kismarton. En insistant sur les livres qui y sont entrés avant la mort de Pál (1713), on pourrait parler d'une collection d'allure fortement protestante. ${ }^{87}$ Or les notes manuscrites que l'on peut relever dans les exemplaires aujourd'hui conservés suggèrent une autre explication au phénomène : il s'agit de livres appartenant aux pasteurs protestants contemporains de la conversion des Esterházy au catholicisme. Nous ne savons pas exactement comment Miklós Esterházy (ou l'un de ses fils) mit la main sur ces livres, mais ce qui est certain, c'est que la famille a conservé la plupart des livres de Pál Czeglédi, ${ }^{88}$ János Kanizsai

\footnotetext{
${ }^{81}$ Monok 2011.

${ }^{82}$ Bobory 2009; Bobory 2019.

${ }^{83}$ Herner-Monok, (szerk.)., Adattár 11, 1983, 505-535.

${ }^{84}$ Balázs M. 1988; Balogh-Horn 2008; Horn 2009.

${ }^{85}$ Péter K. 1985, 128-133; Péter K. 1987.

${ }^{86}$ Herner-Monok, sajtó alá rend., Adattár 11, 1983, 491-495; Monok, KKK I, 1996, 208-210.

${ }^{87}$ Dmitrijeva-Subkov, (hrsg.), Knyigi iz szobranyia. . . 2007; Zvara 2020.

${ }^{88}$ Szelestei Nagy 1987; Zvara 2012.
} 
Pálfi, ${ }^{89}$ István Beythe, ainsi que quelques pièces provenant de la bibliothèque de l'école protestante de Németújvár. ${ }^{90}$ Si nous avions à notre disposition la seule liste des livres, nous serions tentés d'en tirer des conclusions erronées. Pour autant, il faut mettre à l'actif des Esterházy le fait d'avoir conservé ces livres protestants.

Dans les premiers paragraphes de mon introduction, j'ai évoqué la transformation des fonctions de la cour aristocratique d'une époque à l'autre. En l'absence d'une cour royale (qui aurait pu servir d'exemple et organiser la culture à grande échelle) et dans un contexte marqué par de nombreuses conversions religieuses, les cours des grands seigneurs furent chargées de tâches autrement plus importantes qu'auparavant. Il faut également prendre en considération le fait que les structures de l'Église catholique ne se rétablirent véritablement que dans la seconde moitié du XVII ${ }^{\mathrm{e}}$ siècle, permettant enfin aux centres ecclésiastiques de recouvrer un certain nombre des fonctions assurées jusqu'alors par les cours aristocratiques. Ce transfert ne s'est pas nécessairement accompagné d'un allègement des charges financières qui pesaient sur les grandsseigneurs, mais ces derniers se sont du moins trouvés dégagés de certaines obligations quotidiennes. Un sujet de recherche intéressant viserait à étudier quand et comment telle ou telle grande famille a chargé un certain ordre religieux d'accomplir à sa place des missions à caractères pour partie « culturels »- prédication, surveillance des écoles et des imprimeries, etc. Il faudrait aussi déterminer, le cas échéant, pourquoi ces grandes familles ont pu changer d'ordre « favori », comme on l'observe à propos des Nádasdy et des servites, ou des Esterházy et des jésuites, puis des franciscains, etc. Vu sous cet angle, la situation des grands-seigneurs différait fort entre la Hongrie occidentale et la Transylvanie, au moins autant qu'elle différait selon leurs confessions respectives (catholique ou protestante). À la suite de la « décennie tragique » (16601670), la situation des églises protestantes en Hongrie royale fut telle pendant un siècle au moins, qu'elles ont dû bénéficier du soutien indirect, mais constant, de leurs patrons. En Transylvanie, le haut-consistoire de l'Église réformée s'est imposé comme le théâtre sur lequel les grandsseigneurs devaient remplir le rôle politique principal. ${ }^{91}$ Lorsqu'il analyse les fonctions des cours aristocratiques, le chercheur ne saurait faire abstraction de cela.

En guise de synthèse pour cette introduction : lorsque l'on étudie l'histoire de la formation des bibliothèques de l'aristocratie, on doit impérativement prendre en considération le fait que les circonstances historiques dans le bassin des Carpates n'ont guère permis la formation de collections qui, par leur richesse et leur modernité, puissent être comparées à celles des princesélecteurs allemands ou d'autres souverains européens. En revanche, la culture livresque de certains grands-seigneurs de Hongrie n'était nullement en retard par rapport à celle de la noblesse européenne - nous reviendrons sur cette comparaison. En outre, il faut souligner le fait que l'homme public de Hongrie - et c'était le cas de la plupart des nobles hongrois - ne pouvait se permettre de conduire sa vie et de former sa collection de livres uniquement selon son goût personnel. Les possibilités d'acquisition de livres étaient extrêmement limitées, la production locale des imprimés restait très pauvre, la librairie de détail tout à fait rudimentaire (nous n'avons connaissance que de quelques marchands de Haute-Hongrie et de Transylvanie, dont le public était essentiellement bourgeois). Lorsque les agents des éditeurs étrangers (surtout de Vienne,

\footnotetext{
${ }^{89}$ Szelestei Nagy 1987, 125-126; Zvara 2010.

${ }^{90}$ Zvara 2011; Zvara, KKK IX, 2013.

${ }^{91}$ Sipos G. 2000.
} 
d'Allemagne du Sud et d'Italie du Nord) avaient réussi à établir des contacts réguliers avec certaines familles aristocratiques hongroises, leur objectif était de vendre les livres publiés par leur maison-mère et, faute de concurrents, ils y parvenaient en général. Quant aux alumni poursuivant leurs études en Europe aux frais des grands-seigneurs, ils contribuaient certes efficacement à l'enrichissement de la bibliothèque de leur patron, mais leur goût et la nature de leurs études ne manquaient pas non plus de laisser leur empreinte sur les collections aristocratiques.

Pourtant, ces divers facteurs d'influence ne déterminent pas tout, et le propriétaire d'une bibliothèque aristocratique majeure n'était pas privé de la possibilité d'acquérir des livres selon son goût personnel. ${ }^{92}$ Suivant les théories contemporaines relatives à la civilisation de cour, les familles aristocratiques se sont en effet toujours efforcées (à quelques exceptions près) de fonder et entretenir leurs collections dans le but de les rendre accessibles aux savants, enseignants, pasteurs et étudiants de leur entourage. Ces derniers pouvaient de la sorte mieux remplir les fonctions ecclésiastiques ou pédagogiques diverses que les aristocrates leur avaient assignées. Le processus est parfaitement logique, étant donné que les familles qui remplaçaient la cour royale en Hongrie et la cour princière, détruite en Transylvanie (1658), se sont trouvées dans l'obligation de prendre en charge cette tâche. Pour finir, observons que certaines salles de bibliothèque ont été meublées de manière extrêmement somptueuse, les livres furent souvent dotés d'une reliure uniforme et ils portaient un ex libris ; parfois même, les grands-seigneurs ont employé des bibliothécaires « professionnels », notamment pour réorganiser leurs collections, ainsi peut-on repérer dans certaines bibliothèques privées un classement thématique, donnant lieu à la réalisation d'un catalogue et à la mise en place d'un système de cotation. Pour autant, cette pratique a commencé à se généraliser au XVIII ${ }^{\mathrm{e}}$ siècle seulement et l'on ne peut citer aucune bibliothèque privée de la Hongrie ou de la Transylvanie des $\mathrm{XVI}^{\mathrm{e}}$ et XVII ${ }^{\mathrm{e}}$ siècles ayant véritablement rempli cette fonction de représentation. ${ }^{93}$

\section{RÉFÉRENCES}

Adamska, A. and Mostert, M. (Eds.) (2004). The Development of Literate Mentalities in East Central Europe. Brepols. Turnhout.

Bajáki, R., Bujdosó, H., Monok, I., Viskolcz, N., réalisation de l’index: Zvara E. (szerk.) (2009). Magyarországi magánkönyvtárak, IV, 1552-1740. OSZK, Budapest. (Adattár XVI-XVIII. századi szellemi mozgalmaink történetéhez, 13/4).

Balázs, M. (szerk.) (1988). Az erdélyi antitrinitarizmus az 1560-as évek végén [L’antitrinitarisme transylvain à la fin des années 1560]. Akadémiai Kiadó, Budapest. (Humanizmus és reformáció, 14).

Bálint, I.J. (szerk.) (1987). Adalékok a 16-20. századi magyar müvelödés történetéhez [Contribution à l'histoire culturelle hongroise du XVI au XX siecle]. OSZK, Budapest.

Balogh, J. (2005). A székely nemesség kialakulásának folyamata a 17. század elsö felében [Le processus de formation de la noblesse sicule dans la première moitié du XVIIe siècle]. EME, Kolozsvár. (Erdélyi Tudományos Füzetek, 254).

\footnotetext{
${ }^{92}$ Monok 2010.

${ }^{93}$ Monok 2007a.
} 
Balogh, J. and Horn, I. (2008). A hatalomépítés útjai, A homoródszentpáli Kornis család története [La construction du pouvoir en marche, Histoire de la famille Kornis de Homoródszentpál]. Századok, 142: 849-895.

Berding, H. (hrsg.) (1984). Universität und Gesellschaft. Vandenhoeck und Ruprecht, Göttingen.

Berlász, J. (1974). Die Entstehung der ungarischen Bibliothekskultur im 16-17. Jahrhundert. Magyar Könyvszemle, 90: 14-28.

Binder, P. (éd.) (1976). Utazások a régi Európában, Peregrinációs levelek, útleírások és útinaplók (1580-1709). [Voyageurs de l'ancienne Europe. Lettres, journaux. (1580-1709)]. Kriterion, Bukarest.

Bíró, G., Monok, I., and Verók A. (szerk.) (2018). Erdélyi könyvesházak V. 1541-1750, Vegyes források, [Biliothèques de Transylvanie V 1541-1750. Sources diverses]. MTAK, SZTE, Budapest-Szeged. (Adattár XVI-XVIII. századi szellemi mozgalmaink történetéhez 16/5).

Bobory, D. (2009). The Sword and the Crucible: Count Boldizsár Batthyány and Natural Philosophy in Sixteenth-Century Hungary. Cambridge Scholars Publishing, Newcastle upon Tyne.

Bobory, D. (2019). The Correspondence of Boldizsár Batthyány, The Everyday Life of an Early Modern Alchemist. Kronosz, Budapest.

Bödeker, H.E. and Saada, A. (hrsg.) (2007). Bibliothek als Archiv. Vandenhoeck und Ruprecht, Göttingen. (Veröffentlichungen des Max-Planck-Instituts für Geschichte, 221).

Bogdán, I. (1963). A magyarországi papíripar története, 1530-1900 [Histoire de la papeterie en Hongrie, 1530-1900]. Akadémiai Kiadó, Budapest. (A magyar könyv).

Boross, K. (2007). A pozsonyi humanista kör könyvei az Egyetemi Könyvtár antikva-gyüjteményében [Les livres du cercle humaniste de Pozsony aux collections et antiquités de la bibliothèque universitaire]. In: Az Egyetemi Könyvtár Évkönyvei XIII. ELTE EK, Budapest, pp. 157-186.

Borsa, G. (1972). Johannes Manlius könyvkötői tevékenysége, [L’activité de relieur de Johannes Manlius]. In: Az Országos Széchényi Könyvtár Évkönyve 1970-1971. OSZK, Budapest, pp. 301-321; ou encore, in Borsa 2000, 99-113.

Borvölgyi, G. (2004). Ráday Pál (1677-1733) könyvtára [La bibliothèque de Pál Ráday (1677-1733)]. OSZK, SZTE, Budapest-Szeged.(A Kárpát-medence koraújkori könyvtárai - Bibliotheken im Karpatenbecken der frühen Neuzeit, VII).

Buck, A. and Klaniczay, T. (hrsg.) (1987). Das Ende der Renaissance: Europäische Kultur um 1600. Harrassowitz, Wiesbaden. (Wolfenbütteler Anhandlungen zur Renassanceforschung, 6).

Conrads, N. (1982). Ritterakademien der frühen Neuzeit. Bildung als Standesprivileg im 16. und 17. Vandenhoeck und Ruprecht, Jahrhundert, Göttingen.

Csapodi, C. (1984). Ungarische Bibliotheksgeschichte, Vom Mittelalter bis zum Frieden von Szathmár (1711). Gutenberg-Jahrbuch, 58: 332-357.

Csire, M., Erlinghagen, E., Gáti, Z., Pesti, B., and Müller-Funk, W. (hrsg.) (2015). Ein Land mit Eigenschaften, Sprache, Literatur und Kultur in Ungarn in transnationalen Kontexten, Zentraleuropäische Studien für Andrea Seidler. Praesens Verlag, Wien.

Csörsz Rumen, I. (szerk). (2010). Ghesaurus, Tanulmányok Szentmártoni Szabó Géza hatvanadik születésnapjára. MTA ITI, Budapest.

De Benedictis, I. (1998). Per la storia del collezionismo italiano: fonti e documenti .... Ponte alle Grazie, Firenze.

Coordinamento scientifico di Andrea De Pasquale and Atti a cura di Silvana de Capua. (2019). Le Biblioteche anche come Musei: dal Rinascimento ad oggi. BNCR, Roma. (Quaderni della Biblioteca nazionale centrale di Roma, 23). 
Deé Nagy, A. (1996). Könyvgyüjtő asszonyok a XVIII. században [Femmes relieuses au XVIII ${ }^{\mathrm{e}}$ siècle]. In: Kovács, A., Sipos, and Tonk, (szerk.), pp. 134-147.

Katalog, Der Katalog wurde geschafft von Karina A. Dmitrijeva, Nikolaj N. Subkov, et al. (2007). Knyigi iz szobranyia knyazej Esztergazi v moszkovszkih bibliotyekah - Bücher aus der Sammlung der Fürsten Esterházy in Moskauer Bibliotheken. Rudomino, Moszkva.

Dobos, I. and Bene, S. (szerk.) (2009). A magyarságtudományok önértelmezései, [Les études hongroises définies par elles-mêmes]. In: A doktoriskolák II. nemzetközi konferenciája, Budapest, 2008. augusztus 22-24. Nemzetközi Magyarságtudományi Társaság, Budapest.

Ecsedy Judit, V. (1999). A könyvnyomtatás Magyarországon a kézisajtó korában 1473-1800 [L’imprimerie en Hongrie au temps des gazettes artisanales, 1473-1800]. Balassi Kiadó, Budapest.

Ember, G. and Heckenast, G. (föszerk) (1989). Magyarország története, 1686-1790 [L'histoire de la Hongrie 1686-1790]. Akadémiai Kiadó, Budapest.

Etényi Nóra, G. and Horn, I. (szerk.) (2005). Idővel paloták. . Magyar udvari kultúra a 16-17. században [Les palais à travers le temps... La culture de cour en Hongrie aux XVI et XVII siècles]. Balassi Kiadó, Budapest.

Etényi Nóra, G. and Horn, I. (szerk.) (2008). Portré és imázs, Politikai propaganda és reprezentáció a kora újkorban [Portaits et images. La propagande et les représentations politiques aux Temps modernes]. L'Harmattan, Budapest.

Etényi Nóra, G. and Horn, I. (szerk.) (2010). Színlelés és rejtözködés, A kora újkori magyar politika szerepjátszásai [Simulation et dissimulation dans le jeu de rôle politique des Temps modernes en Hongrie]. L'Harmattan, Budapest.

Evans, R. (1975). The Wechel Presses, Humanism and Calvinism in Central Europe 1572-1627. Oxford, Past and Present Soc. (Past and Present. Supplement, 2.).

Farkas, G., Katona, T., Latzkovits, M., and Varga, A. (1992). Magyarországi magánkönyvtárak, II, (1580-1721) [Les bibliothèques privées hongroises, II, (1580-1721)]. Szeged. (Adattár XVI-XVIII. századi szellemi mozgalmaink történetéhez, 13/2).

Fatsar, K. (2008). Magyarországi barokk kertmüvészet [L'art du jardin baroque en Hongrie]. Helikon, Budapest.

Fazekas, I. (2001). Count Ádám Batthyány I and his Children. In: Péter, K. (Ed.), Beloved Children, pp. 163-197.

Fehér, J. (kiad.) (2007). Teleki Mihály udvartartási naplója (1673-1681) [Le journal d'exploitation de Mihály Teleki]. Entz Géza Művelődéstörténeti Alapítvány, Kolozsvár. (Erdélyi művelődéstörténeti források, 5.).

Fülemüle, Á. and Kiss, R. (szerk.) (2008). Történeti forrás - néprajzi olvasat [Sources historiques - Lectures sur la culture populaire]. L'Harmattan, Budapest. (Documentatio ethnographica, 23).

Fundárková, Á. and Fazekas, I. (hrsg.) (2013). Die weltliche und kirchliche Elite aus dem Königreich Böhmen und Königreich Ungarn am Wiener Kaiserhof im 16.-17. Jahrhundert, Wien. (Publikationen der Ungarischen Geschichtsforschung in Wien, VIII).

Gilányi, G. (2019). Mozaikok Erdély ismeretlen gregorián hagyományából: Egy Anjou-kori antifonále töredékei Erdélyben - Mosaics of the plainchant tradition of Transylvania: Interpreting the 14th-century antiphoner fragments at Güssing. BTK, Zenetudományi Intézet, Budapest. (Resonemus pariter, Mühelytanulmányok a középkori zenetörténethez - Studies in Medieval Music History, 1).

Görtler, W. and Kropf, R. (hrsg.) (2009). Die Familie Esterházy im 17. und 18. Jahrhundert, Eisenstadt. (Wissenschaftliche Arbeiten aus dem Burgenland, 128).

Grell, C., Paravicini, W., and Voss, J. (1998). Les princes et l'histoire du XIVe au XVIIIe siècle. In: Actes du colloque organisé par l'Université de Versailles-Saint Quentin et l'Institut Historique Allemand, Paris/ Versailles, 13-16 mars 1996, publiés sous la dir. Bouvier, Bonn. (Pariser historische Studien, 47). 
Grüll, T., Keveházi, K., Kokas, K., Monok, I., Ötvös, P., and Prickler, H. (hrsg) (1996). Lesestoffe in Westungarn II, Forchtenstein (Fraknó), Eisenstadt (Kismarton), Güns (Köszeg), Rust (Ruszt). Szeged. (Adattár XVI-XVIII. századi szellemi mozgalmaink történetéhez 18/2. - Burgenländische Forschungen, Sonderband XV).

a cura di Guida, F. (1996). Dalla liberazione di Buda all'Ungheria del Trianon, Ungheria e Italia tra età moderna e contemporanea, Atti del Convegno storico italo-ungherese (Pécs 23-24 aprile 1993), a cura di Francesco Guida, Roma, Lithos, 1996, 64-71.

Halmágyi, M. (2009). Önazonosság és idegenfelfogás a korai magyar történetírásban és ennek európai összefüggései, [Références domestiques et étrangères (européennes) dans l'historiographie hongroise des Temps modernes]. In: Dobos and Bene, szerk., A magyarságtudományok. .., pp. 9-23.

Hausner, G. (2009). Pálffy Pál. In: MAMÛL IX, 7-10.

Hausner, G., Klaniczay, T., Kovács, S.I., Monok, I., and Orlovszky, G. (Eds.) (1991). A Bibliotheca Zriniana története és állománya - History and Stock of the Bibliotheca Zriniana. Zrínyi Kiadó, Budapest. (Zrínyi könyvtár, 4).

Hegyi, Á. and Simon, M. (szerk.) (2008). Apró cseppekböl lesz a zápor”, Bakonyi Géza emlékkönyv. Szeged, Szegedi Egyetemi Kiadó, Juhász Gyula Felsőoktatási Kiadó. (Habent sua fata libelli, IV).

dossier réalisé par Herner J. and Monok I. (1983). A magyar könyvkultúra múltjából, Iványi Béla cikkei és anyaggyüjtése [La culture du livre en Hongrie au temps jadis, articles de Béla Iványi], dossier réalisé par Herner János, Monok István, Szeged, JATE, 1983 (Adattár XVI-XVIII. századi szellemi mozgalmaink történetéhez, 11).

Hoffmann, G. (szerk) (1980). Peregrinuslevelek (1711-1750), Külföldön tanuló diákok levelei Teleki Sándornak [Lettres de pèlerins (1711-1750), lettres d'étudiants à l'étranger à Sándor Teleki], dossier réalisé sous la direction de Jankovics József, avec la collaboration de Bálint Judit, Bujtás László, Hoffmann Gizella, Horváth Zsuzsanna, Küri Erika, Mihalics Veronika, Udvardi Ágnes. Traductions du latin par Bartók István. JATE, Szeged. (Adattár XVI-XVIII. századi szellemi mozgalmaink történetéhez, $6)$.

Horn, I. (2009). Hit és hatalom Az erdélyi unitárius nemesség 16. századi története [La foi et le pouvoir. Histoire de la noblesse unitarienne en Transylvanie au XVIe siècle]. Balassi Kiadó, Transylvania Emlékeiért Tudományos Egyesület, Budapest.

Horn, I. (2010). A fónemesi iskoláztatás változásai az Erdélyi Fejedelemségben [L'évolution de la scolarisation au sein de la haute noblesse dans la principauté transylvaine]. In: Barokk, Történelem-IrodalomMüvészet, Különszám, Warszawa, Wydawnictwo Neriton, 109-124.

Imre, M., Oláh, S., Fazakas, G.T., and Száraz, O. (szerk.) (2011) Eruditio, virtus et constantia, Tanulmányok a 70 éves Bitskey István tiszteletére. Debreceni Egyetemi Kiadó, Debrecen.

Kaufmann, G. (hrsg.) (1991). Die Renaissance im Blick der Nationen Europas. Harrassowitz: Wiesbaden (Wolfenbütteler Abhandlungen zur Renaissanceforschung, 9).

Klaniczay, T. (1985). Les intellectuels dans un pays sans universités (Hongrie: XVI siècle). In: Köpeczi-Le, G. (Ed.), Intellectuels..., pp. 99-109.

Klaniczay, T. (1991). Die Soziale und institutionelle Infrastruktur der ungarischen Renaissance. In: Kaufmann, hrsg. Die Renaissance im Blick..., pp. 319-338.

Klaniczay, G. and Pócs, E. (2008). Witchcraft Mythologies and Persecutions. CEU Press, Budapest.

Kókay, G. (1990). Geschichte des Buchhandels in Ungarn. Otto Harrassowitz, Wiesbaden.

dossier réalisé par Koltai, A. (2001). Magyar udvari rendtartás, Utasitások és rendeletek 1617-1708

[L'étiquette de la cour hongroise. Instructions et règlements (1617-1708)]. Budapest, Osiris Kiadó. (Milleniumi magyar történelem). 
Koltai, A. (2002). Batthyány Ádám és könyvtára - Die Bibliothek von Ádám Batthyány. OSZK-Scriptum, Budapest-Szeged. (A Kárpát-medence koraújkori könyvtárai - Bibliotheken im Karpatenbecken der frühen Neuzeit, IV).

Koltai, A (2008). Portré végvidékkel, Batthyány Ádám és a képzőmüvészet (1636-1659) [La pratique du portrait dans une région frontalière. Ádám Batthyány et les Beaux-Arts (1636-1659)]. In: Etényi and Horn, szerk., Portré és imázs. ., pp. 401-435.

Koltai, A. (2013). Hof und Hofordnung in Ungarn des 17. Jahrhundert. In: Fundárková and Fazekas, hrsg., Die weltliche..., pp. 217-250.

Koltai, A. and Batthyányi, Á. (2012). Egy magyar fóúr és udvara a XVII. század közepén, [Ádám Batthyány. Un magnat hongrois et sa cour au milieu du XVII siecle], Györ. (A Győri Egyházmegyei Levéltár kiadványai, Források, feldolgozások, 14).

Köpeczi, B. (1996). A Rákóczi-szabadságharc és Magyarország [Les guerres d’indépendance de Rákóczi et la Hongrie]. Akadémiai Kiadó, Budapest.

Köpeczi, B. (1976). „Magyarország a kereszténység ellensége”. A Thököly felkelés az európai közvéleményben ["La Hongrie, cet ennemi de la Chrétienté ». Le soulèvement de Thököly dans l'opinion européenne]. Akadémiai Kiadó, Budapest.

Köpeczi, B. (főszerk) (1986). Erdély története [Histoire de la Transylvanie]. Akadémiai Kiadó, Budapest.

Köpeczi, B. (Ed.) (1994). History of Transylvania. Akadémiai Kiadó, Budapest.

Köpeczi, B. and Le Goff, J. (Eds.) (1985). Intellectuels français, intellectuels hongrois. Akadémiai Kiadó, CNRS, Budapest-Paris.

Koppány, T. (1990). 17. századi épitési megállapodások a Batthyány levéltárból [Les contrats de construction conservés dans les archives du XVIIe siècle]. Lymbus, Müvelödéstörténeti Tár, II, Szeged, pp. 143-159. (Klny.: A Lymbus füzetei, 15).

Koppány, T. (1991/2001). Müvészek és mesterek a Batthyány-család 16-17. századi építkezésein [Les artistes et artisans impliqués dans les constructions réalisées par la famille Batthyány aux XVI ${ }^{\mathrm{e}}$ et XVII ${ }^{\mathrm{e}}$ siècles]. Magyar müemlékvédelem, II: 173-194.

Koppány, T. (2006). Batthyány II. Ferenc és Poppel Éva építkezései [Les constructions de Ferenc II. Batthyány et d’Éva Poppel]. In: Nagy, Z., szerk., A Batthyányak...pp., 89-114.

Koppány, T. and Batthyány, I (1984). Ádám építkezései, 1629-1659 [Les constructions réalisées par Ádám I. Batthyány]. Történelmi Szemle, 27: 539-555.

Körner, S. (2011). Esterházy Feenreich, Fürst Nikolaus I. verblüfft Europa. Michael Imhof Verlag, Eisenstadt.

Körner, S. and Perschy, J. (hrsg.) (2006). Blaues Blut und Druckerschwärze, Aristokratische Büchersammlungen von 1500 bis 1700. Esterházy Privatstiftung, Eisenstadt.

publié par Kovács, I. (1987). Début et fin des Lumières en Hongrie, en Europe Centrale et en Europe Orientale. In: Actes du sixième colloque de Mátrafüred, 20-25 octobre 1984, Budapest-Paris, Akadémiai Kiadó, CNRS.

Kovács, S.I. (1988). Szakácsmesterségnek és utazásnak könyvecskéi [Les manuels de voyage et de cuisine]. Szépirodalmi Kiadó, Budapest.

Kovács, A., Sipos, G. and Tonk, S. (szerk.) (1996). Emlékkönyv Jakó Zsigmond nyolcvanadik születésnapjára. EME, Kolozsvár.

Kriegleder, W., Andrea, S., and Jozef, T. (hrsg.) (2007). Deutsche Sprache und Kultur in der Zips. Édition Lumière, Bremen. (Presse und Geschichte - Neue Beiträge, 24).

Kristóf, I. (1990). Wise women, sinners and the poor: the social background of witsch-hunting in a 16/18thcentury Calvinist City of Eastern-Hungary. Acta Ethnographica Hungarica, 37, pp. 93-119. 
Kristóf, I. (1995). „Istenes könyvek - ördöngös könyvek” [Livres divins, livres sataniques]. Népi kultúra népi társadalom, 18: 67-104.

Sz. Kristóf, I. (2002). A számoktól a (jogi) szövegekig, Alfabetizációtörténet, olvasástörténet vagy kommunikációtörténet? [Des chiffres et des lettres (juridiques), histoire de l'alphabétisation, de la lecture et de la communication ?]. Acta Papensia, A Pápai Református gyüjtemények közleményei, 2: 1-2, 3-28.

Kristóf, I. (2008). How to Make a (Legal) Pact with the Devil? Legal Customs and Literacy in Witsch Confessions in Early Modern Hungary. In: Klaniczay, G. and Pócs (Eds.), Witchcraft..., pp. 164-183.

Sz. Kristóf, I. (2008). Statisztikák, használatok, olvasatok. Az írni-olvasni tudás történeti kutatásának forrásairól és módszereiről 16-18. század [Statistiques, usages, lectures. Les sources et méthodes de la recherche historique sur la pratique de la lecture et de l'écriture]. In: Fülemüle and Kiss, szerk., Történeti forrás..., pp. 209-224.

Kropf, R. and Schlag, G. (1998). Adelige Hofhaltung im österreichisch-ungarischen Grenzraum. In: Symposium im Rahmen der ,Schlaininger Gespräche” vom 20-23. September 1995 auf Burg Schlaining. Burgenländisches Landesmuseum Eisenstadt, Eisenstadt. (Wissenschaftliche Arbeiten aus dem Burgenland, 98).

Kruse, H. and Paravicini, W. (hrsg) (1999). Höfe und Hofordnungen, 5. In: Symposium der RezidenzenKommission der Akademie der Wissenschaften in Göttingen, veranstaltet gemeinsam mit dem Deutschen Historischen Institut Paris und dem Staatsarchiv Sigmaringen, Sigmaringen, 5. bis 8. Oktober 1996. Sigmaringen, Jan Thorbecke Verlag. (Rezidenzenforschung, 10).

Kumaniecki, C. (Ed.) (1953). Modrevius Andreas Frisius, Commentariorum de republica emendanda libri quinque, Vol. I. PIW Warszawa.

Kumorovitz, L.B., Kállai Erzsébet, M., Munkatárs Belényesy Mária, Gádorján Alice, Fasc. I-II (kiad) (1959). Kultúrtörténeti szemelvények a Nádasdiak 1540-1550-es számadásaiból [Fragments d'histoire culturelle extraits de la comptabilité des Nádasdy en 1540-1550]. Magyar Nemzeti Múzeum, Magyar Néprajzi Múzeum, Budapest. (Történeti és néprajzi füzetek, I).

Lajos, K. (2007). A XVIII. század magyarságképe elfeledett francia források tükrében, [L’image des Hongrois $d u$ XVIII siècle dans le miroir des sources françaises négligées]. JATEPress, Szeged.

dir. por María López-Vidriero, L. and Cátedra, P.M. (1998). Coleccionismo y bibliotecas (siglos XV-XVIII). Universidad de Salamanca, Salamanca.

Lukinich, I. (1911). Bethlen Péter iskoláztatásához [Sur les études de Péter Bethlen]. Történelmi Tár, 49: 305-310.

Lukinich, I. (1926). A Bethlen-fiúk külföldi iskoláztatása [Les études à l'étranger des garçons de la famille Bethlen]. In: Lukinich (szerk.), Nagyenyedi..., pp. 79-100.

Lukinich, I. (szerk.) (1926a). Nagyenyedi album. Budapest, Nagyenyedi Diákok Egyesülete.

dossier et introduction de Makkai, L. (1954). I. Rákóczi György birtokainak gazdasági iratai (1631-1648) [Archives économiques sur les propriétés de György I. Rákóczi]. Akadémiai Kiadó, Budapest.

MAMÜL I-XIV (2003-2014). Magyar müvelődéstörténeti lexikon, Középkor és kora újkor, I-XIV. kötet, föszerk. Köszeghy Péter, Balassi, Budapest.

Monok, I. (1983). Csanaki Máté könyvjegyzéke [Le répertoire des livres de Máté Csanaki], Magyar Könyvszemle, 99, 256-262.

Monok, I. (1989). A Belga Királyi Könyvtár magyar vonatkozású útleírásai [Les références à la Hongrie dans la bibliothèque royale de Belgique]. Lymbus, Müvelödéstörténeti Tár, I, Szeged, pp. 37-76. (Klny.: A Lymbus Füzetei 3).

Monok, I. (1989a). Egy flamand utazó pozsonyi élményei 1662-ből - De belevenissen van een Vlaams reiziger in Pozsony (1662). Erasmus, 1(1): 31-34. 
Monok, I. (1990). Adalékok iktári Bethlen Péter peregrinációja történetéhez, I, Idősb Bethlen István levelei 1625-1628 [Contribution à l'histoire des pérégrinations de Péter Bethlen de Iktar, correspondance de István Bethen l’ancien 1625-1628]. Ráday Gyüjtemény Évkönyve, VI: 193-205.

Monok, I. (1990a). Újabb adatok id. Bethlen István patrónusi tevékenységéhez [Nouvelles sources sur les activités de patronage de István Bethlen]. Ráday Gyüjtemény Évkönyve, VI: 208-209.

Monok, I. (1994). A magyarországi főnemesség könyvgyüjtési szokásai a XVI-XVII. században [L’achat de livres aux XVIe et XVIIe siècles. Les usages de la haute noblesse hongroise]. In:CaféBábel, 14. kötet (Gyüjtés), 4: 59-68.

Monok, I. (2003). Die Bibliothek des Johann Jacob Knaus, Die Reste einer württenbergischen protestantischen Bibliothek in Güssing. Jahrbuch des Ungarischen Kulturinstitutes in Stuttgart, 1: 138-146.

Monok, I. (2004). Die kulturvermittelnde Rolle des Batthyány-Hofes an der Wende vom 16. zum 17. Jahrhundert. In: Kriegleder and Seidler, hrsg., Deutsche Sprache und Kultur..., 2004, pp. 75-90.

Monok, I. (2004a). Exulanten aus Bayern, Oberpfalz und Pfalz am Batthyány-Hof an der Wende des 16. und 17. Jahrhunderts. Ungarn Jahrbuch, 27: 331-340.

Monok, I. (2005). The Bánffy Family's Court in Alsólindva and its Book Culture - The Nádasdy Courts in Sárvár and Pottendorff and their Book Culture - The Batthyány Court in Németújvár and its Book Culture. In: Monok, (Ed.), Blue Blood..., pp. 61-104.

Monok, I. (2006). Hof- und Buchkultur der Familie Bánffy in Unterlimbach, - Hof- und Buchkultur der Familie Nádasdy in Sárvár und Pottendorf, - Hof- und Buchkultur der Familie Batthyány in Güssing. In Körner and Perschy, hrsg., Blaues Blut..., pp. 62-109.

Monok, I. (2007). Lesestoffe in Leutschau im Vergleich. XVI-XVII. Jahrhundert. In: Kriegleder, Seidler and Tanzer, hrsg., Deutsche Sprache..., pp. 157-169.

Monok, I. (2007a). Qu'est-ce qu'un bibliothécaire en Hongrie à l'époque moderne (XVI $-X V I I I^{e}$ siècle)? in Histoire et civilisation du livre. Revue internationale, 3: 319-328.

Monok, I. (2008). Die Buch- und Lesekultur in Ungarn der frühen Neuzeit, Teilbilanz der Ergebnisse einer langen Grundlagenforschung (1980-2007). Mitteilungen der Gesellschaft für Buchforschung in Österreich, 10(1): 7-31.

Monok, I. (2010). Udvartartási minták, korszerű ismeretanyag a 16-17. század fordulójának foúri könyvtáraiban Magyarországon. In: Etényi and Horn (szerk.), Színlelés..., 67-76.

Monok, I. (2011). Boldizsár (Balthasar) Batthyány, un homme de culture française. In: Nencescu, Macarie, and Radu, réd., 300 ans après. .., pp. 348-366.

Monok, I. (2011a). Les bibliothèques et la lecture dans le Bassin des Carpates, 1526-1750. Champion, Paris. (Bibliothèque d'études de l'Europe centrale, 4).

Monok, I. (2012). L'uso pubblico dei libri nell'Ungheria del Cinque e Seicento. La Bibliofilía, CXIV, 2: 215229.

Monok, I. (2015). What Makes a Library in Hungary or Transylvania Modern in the Early Modern Age? Some Aspects of Assessment. In: Csire, Erlinghagen, Gát, Pesti, and Müller-Funk, hrsg., Ein land..., 2015, pp. 131-140.

Monok, I. (2016). Female Book Owners and Female Readers in Sixteenth- and Seventeenth-Century Hungary. SHARP, The Society for the History of Autorship, Reading and Publishing, Translations 2, Ed. by Pickford, S. and Lyons M. http://www.sharpweb.org/main/sharp-translations.

Monok, I. (2019). Le musée de la bibliothèque ou la bibliothèque du musée ? Une histoire de l'Europe centrale, avec des exemples hongrois. In: De Pasquale and Capua, a cura di, Le Biblioteche. . pp., 19-29.

Monok, I. (Ed.) (2005). Blue Blood, Black Ink, Book Collections of Aristocratic Families from 1500 to 1700. OSZK, Budapest. 
Monok, I. (1996). A Rákóczi-család könyvtárai - Bibliotheken der Familie-Rákóczi, 1588-1660. Scriptum, Szeged. (A Kárpát-medence koraújkori könyvtárai - Bibliotheken im Karpatenbecken der frühen Neuzeit, I).

dossier réalisé par Monok, I., Németh, N. and Tonk, S. (1991). Erdélyi könyvesházak II, Kolozsvár, Marosvásárhely, Nagyenyed, Szászváros, Székelyudvarhely [Bibliothèques transylvaines II, ...]. Scriptum, Szeged. (Adattár XVI-XVIII. századi szellemi mozgalmaink történetéhez, 16/2.).

dossier réalisé par Monok, I., Németh, N., Varga, A. (1994). Erdélyi könyvesházak III, 1563-1757, A Bethlen-család és környezete, Az Apafi-család és környezete, A Teleki-család és környezete, Vegyes források, [könyvesházak [Bibliothèques transylvaines III, ...]. Szeged, Scriptum. (Adattár XVI-XVIII. századi szellemi mozgalmaink történetéhez, 16/3).

Monok, I., Ötvös, P., Band II, Monok, I., Ötvös, P., and Zvara, E. (hrsg.) (2004). Bibliotheken in Güssing im 16. und 17. Jahrhundert. Balthasar Batthyány und seine Bibliothek. Eisenstadt (Burgenländische Forschungen, Sonderband XXVI).

Monok, I. and Seidler, A. (hrsg.) (2020). Reformation und Bücher, Zentren der Ideen - Zentren der Buchproduktion. Harrassowitz, Wiesbaden. (Wolfenbütteler Abhandlungen zur Geschichte des Buchwesens, 51).

Monok, I. and Zvara, E. (2020). Esterhasiana Biblioteca. MTAK, Kossuth, Budapest. (Esterházyana).

Müller, R.A. (1984). Aristokratisierung des Studiums? Bemerkungen zur Adelsfrequenz an süddeutschen Universitäten im 17. Jahrhunderts. In: Berding, hrsg., Universität und Gesellschaft, pp. 31-46.

Müller, R.A. (1998).Historia als Regentenhilfe. Geschichte als Bildungsfach in deutschen Fürstenspiegen des konfessionellen Zeitalters. In: Grell, Paravicini and Voss, sous la dir. de, Les princes. .., pp. 359-372.

Nencescu, M., Macarie, I., and Radu, C. (réd) (2011). Travaux du symposium international Le livre, La Roumanie, L'Europe, Troisième édition, 20-24. septembre 2010, 300 ans après l'intronisation de l'érudit roumain Dimitrie Cantemir en Moldavie, Tome I. Bibliothèque de Bucarest, Bucarest.

Ötvös, P. (1980). A Csáky-énekeskönyv [Le livre de chant Csáky]. Irodalomtörténeti Közlemények, 84: 486-509.

Ötvös, P. (1988). Egy foúri könyvtár a XVII. század elején, Illésházy István [Une bibliothèque seigneuriale au début du XVIIe siècle, István Illésházy]. In: Zombori, szerk., Az értelmiség. .., pp. 149-157.

Ötvös, P. (1999). Aktualisierung alter Klischees: Die Ungarn auf der Völkertalfel. In: Stenzel, hrsg., Europäischer Völkerspiegel..., pp. 265-282.

Ötvös, P. (kiad.) (1988). Széchenyi Zsigmond itáliai körútja 1699-1700 [Le voyage de Zsigmond Széchenyi en Italie 1699-1700]. JATE, Szeged. (Peregrinatio Hungarorum, 1).

Öze, S. (Kiad.) (1996). 500 magyar levél a XVI. századból, Csányi Ákos levelei Nádasdy Tamáshoz 15491562, I-II. kötet [500 lettres hongroises du XVIe siècle, lettres d’Ákos Csányi à Tamás Nádasdy 15491562]. Budapest, Magyar Nemzeti Múzeum.

Pajkossy, G. (1983). Ellebodius és baráti körének könyvei az Egyetemi Könyvtárban [Les livres du cercle amical d'Ellebodius à la bibliothèque universitaire]. Magyar Könyvszemle, 99: 225-242.

Katalog, red. von Perschy, J. (1995). Die Fürsten Esterházy, Magnaten, Diplomate und Mäzene, Austellung, Eisenstadt, 28. 4. bis 31. 10 1995. Eisenstadt. (Burgenländische Forschungen, Sonderband XVI).

Pesti, B. (4/2009). Erbauungsliteratur und weibliches Lesepublikum. Lesegewohnheiten von Frauen des 17. Jahrhunderts in Ungarn, WEBFU (Wiener elektronische Beiträge des Instituts für Finno-Ugristik), Sondernummer. https://www.univie.ac.at/webfu/texte/4Pesti.pdf.

Pesti, B. (2010). „Kegyes patróna asszonyaink”, Női mecenatúra Magyarországon a XVII. század első felében, [ "Vos grâces, dames patronnesses », le mécénat féminin en Hongrie dans la première moitié du XVIIe siècle]. In: Rumen, C, szerk., Ghesaurus. .., pp. 359-368. 
Pesti, B. (2013). Dedikáció és mecenatúra Magyarországon a 17. század elsö felében [Dédicaces et mécénat en Hongrie dans la première moitié du XVIIe siècle]. Kossuth Kiadó, EKF, Budapest-Eger. (Kulturális örökség).

Péter, K. (1985). A magyar romlásnak századában [Le siècle de l'écroulement de la Hongrie]. Gondolat, Budapest.

Péter, K. (1986). A korlátlan fejedelmi hatalom alatt éló társadalom [La société sous la monarchie absolue]. In: Köpeczi, föszerk., Erdély története, pp. 726-782.

Péter, K. (1987). Der rosenkreuzerische Patriotismus, Die Verbreitung der Ideen der Rosenkreuzer in Mittel- und Osteuropa. In: Buck and Klaniczay, hrsg., Das Ende. .., pp. 125-133.

Péter, K. (1989). Könyvek, olvasók, értelmiség [Lettrés, lecteurs, intellectuels]. In: Ember and Heckenast, föszerk., Magyarország története..., pp. 544-548.

Péter, K. (1989a). Udvari-foúri kultúra [La culture de la cour et de la haute-noblesse]. In: Ember and Heckenast, föszerk., Magyarország története. .., pp. 573-577.

Péter, K. (Ed.) (2001). Beloved Children, History of Aristocratic Childhood in Hungary in the Early Modern Age. CEU Press, Budapest.

Pócs, É. (szerk.) (2001). Áldás és átok, csoda és boszorkányság [Bénédiction et malédiction, miracles et sorcellerie]. Balassi Kiadó, Budapest. (Tanulmányok a transzcendensröl, IV).

Raabe, P. (1982). Bibliotheksgeschichte und historische Leserforschung, Anmerkungen zu einem Forschungsthema. Wolfenbütteler Notizen zur Buchgeschichte, 7: 433-441.

Raabe, P. (1984). Bibliothekskataloge als buchgeschichtliche Quellen, Bemerkungen über gedruckte Kataloge öffentlicher Bibliotheken in der frühen Neuzeit. In Wittmann, hrsg., Bücherkataloge..., pp. 275-297.

Raffler, M. (2007). Museum Spiegel der Nation? Zugänge zur Historischen Museologie am Beispiel der Genese von Landes- und Nationalmuseum in der Habsburgermonarchie. Böhlau Verlag, Wien-Köln-Graz.

Ranum, O. (1998). L'histoire entre la pédagogie et la philosophie des années 1630-1640. In: Grell, Paravicini, Voss, sous la dir. de, Les princes..., pp. 473-482.

Ribard, D. (2007). Livres, pouvoir et théorie, Comptabilité et noblesse en France á la fin du XVIIe siècle, Revue de Synthèse, 128(1-2): 97-122.

Sárdi, M. (2004). Főrangú hölgyek gyógyfüves könyvei [Les livres médicinaux des grandes dames]. In: Pócs, szerk., Áldás és átok. .., pp. 203-222.

Sipos, G. (2000). Az Erdélyi Református Fókonzisztórium kialakulása 1668-1713-(1736) [La genèse du consistoire réformé de Transylvanie 1668-1713-(1736)]. Erdélyi Múzeum Egyesület, Kolozsvár. (Erdélyi Tudományos Füzetek, 230).

Soltész, E. (1974). Über die gesellschaftliche Funktion des Buches in Ungarn. In: Swierk, hrsg., Beiträge zur Geschichte des Buches..., pp. 268-279.

Soltész, Z. (1995). Révay Mártonné Esterházy Zsófia Isocrates-kötetének kötése és későbbi possessorai [Le livre d’Isocrate de Zsófia Esterházy, épouse Márton Révay, et ses possesseurs successifs]. Magyar Könyvszemle, 111: 131-141.

Söptei, I. (szerk.) (1998). Nádasdy Tamás (1498-1562) emlékezete, 500 éve született Magyarország nádora, [En souvenir du palatin, Tamás Nádasdy (1498-1562), à l’occasion de son 500e anniversaire]. Nádasdy Ferenc Múzeum, Sárvár.

Stenzel, F.K. (hrsg.) (1999). Völkerspiegel, 1999 Europäischer Völkerspiegel, Imagologisch-etnographische Studien zu den Völkertafeln des 18. Jahrhunderts. Winter, Heidelberg.

Swierk, A.G. (hrsg.) (1974). Beiträge zur Geschichte des Buches und seiner Funktion in der Gesellschaft, Festschrift für Hans Widmann zum 65. Geburtstag am 28. März 1973. Hiersemann, Stuttgart. 
Szelestei, N.L. (1987). Ceglédi Szabó Pál dunántúli református püspök könyvtárának kötetei [La bibliothèque de Pál Ceglédi Szabó, évêque réformé de l'arrondissement ecclésiastique de Dunantúl]. In: Bálint, szerk., Adalékok. ., pp. 98-128.

Szelestei, N.L. (kiad.) (1988). Batthyány Kristóf európai utazása 1657-1658 [Les voyages en Europe de Kristóf Batthyány]. JATE, Szeged. (Peregrinatio Hungarorum, 2).

Szilágyi, S. (1870). Alvinczi Péter okmánytára - Diplomatarium Alvinczianum. Eggenberger, Pest. (Magyar Történelmi Emlékek - Monumenta Hungariae Historica, 1. osztály, Okmánytárak, 14/15).

Szőnyi, Gy.E. (Spring 1985). Hermetic Books in Sixteenth-Century Hungary. Cauda Pavonis, Studies in Hermeticism (Washington State University), 4(1): 1-3.

Teutsch, F. (1879). Geschichte des deutschen Buchhandels in Siebenbürgen. Archiv für Geschichte des deutschen Buchhandels, 4: 13-27; 6(1881), 7-71.; 15(1892), 103-188. (reprint: Nendeln/Lichtenstein, Kraus, 1977).

Tolnai, G. (1986). Transylvania and the Nederlands, at the end of the XVIIth century. Acta Litteraria Academiae Scientiarum Hungaricarum, 28 (3-4): 253-260.

Toma, K. (2005). Nádasdy István európai tanulmányútja (1669-1670), A Kavalierstour alkalmazása a magyar nevelési gyakorlatban. In: Etényi and Horn, szerk., Idóvel paloták. .., pp. 192-214.

a cura di Tortorelli, G. (2002). Biblioteche nobiliari e circolazione del libro tra Settecento e Ottocento. In: Atti del Convegno nazionale di studio, Perugia, 29-30 giugno 2001. Pendragos, Bologna.

Tóth, I.Gy. (1987). L'alphabétisation des paysans en Transdanubie occidentale au temps des Lumières. In: Kovács, I., publ. par, Début et fin des Lumières..., pp. 293-300.

Tóth, I.Gy. (1993). How many Hungarian noblemen could read in the eighteenth century? CEU History Department yearbook, Budapest, pp. 67-79.

Tóth, I.Gy. (1996). Literacy and Written Culture in Early Modern Central Europe. CEU Press, Budapest.

Tóth, I.Gy. (1996a). La diffusione dell'alfabetizzazione nel comitato di Vas nei secoli XVII-XIX. In: Guida, a cura di, Dalla liberazione di Buda..., pp. 64-71.

Tóth, I.Gy. (2004). Illiterate and Latin-speaking gentlemen. In: Adamska and Moster, (Eds.), The development..., pp. 519-528.

Tüdős, S.K. (1998). Székely fónemesi életmód a XVII. század alkonyán [Le mode de vie des grandes familles nobles sicules à la fin du XVIIe siècle]. Kriterion Könyvkiadó, Bukarest-Kolozsvár.

Tüdős, S.K. (kiad.) (2006-2008). Erdélyi testamentumok, 2-3. kötet, Erdélyi nemesek és fóemberek végrendeletei, XVI. század; 1600-1660 [Les testaments au sein de la noblesse et de l'aristocratie transylvaine au XVIe siècle, 1600-1660]. Marosvásárhely, Mentor Kiadó. (Erdély emlékezete).

Tüdős, S.K. (2009). A régi gernyeszegi várkastély, [Le château fort de Gernyeszeg]. de Marosvásárhely, Mentor Kiadó.

Ursuţiu, M. (kiad.) (1983). Rétyi Péter naplója [Le journal de Péter Rétyi]. Kriterion Kiadó, Bukarest. (Téka).

Várkonyi Ágnes, R. (1986). Iskolák, könyvtárak, nyomdák [Écoles, bibliothèques, imprimeries], In: Köpeczi, föszerk. Erdély története, pp. 935-940.

Várkonyi Ágnes, R. (szerk.) (1987). Magyar reneszánsz udvari kultúra, [La culture curiale en Hongrie à la Renaissance]. Gondolat, Budapest.

Várkonyi Ágnes, R. (1989). Intézmények, iskolák, könyvtárak, nyomdák [Institutions, écoles, bibliothèques, imprimeries], In: Ember and Heckenast, föszerk., Magyarország története. .., pp. 298-305.

Várkonyi Ágnes, R. (2010). Európa Zrínyije, Válogatott tanulmányok [L’Europe de Zrínyi. Sélections d'études]. Argumentum, Budapest. 
Vass, M. (1912). Kornis György külföldi tanulása, (Adalék külföldi iskolázásunk történetéhez), [Les études à l'étranger de György Kornis (contribution à l'histoire de la scolarisation à l'étranger)]. Keresztény Magvetö, 47: 209-229.

Viskolcz, N. (2011). Nádasdy Ferenc Rómában [Ferenc Nádasdy à Rome]. In: Imre, Oláh Sz., Fazakas, and Száraz, szerk., Eruditio, virtus. ., pp. 340-349.

Viskolcz, N. (2013). A mecenatúra szinterei a fóuri udvarban, Nádasdy Ferenc könyvtára [Le mécénat aristocratique sur la scène, la bibliothèque de Ferenc Nádasdy]. SZTE, HEH, Szeged-Budapest. (A Kárpát-medence koraújkori könyvtárai - Bibliotheken im Karpatenbecken der frühen Neuzeit, VIII).

Wiesner, J. (1913). Der ungarische Buchhandel, hrsg. durch den Vorbereitende Komitee der 8. Tagung des Internationales Verleger-Kongresses, Budapest, Hornyánszky.

Wittmann, R. (hrsg.) (1984). Bücherkataloge als buchgeschichtliche Quellen in der frühen Neuzeit. Harrassowitz, Wiesbaden. (Wolfenbütteler Schriften zur Geschichte des Buchwesens, 10).

Zimányi, V. (1998). Die Hofhaltung und Lebensweise der Esterházy im XVII. Jahrhundert. In: Kropf and Schlag, red., Adelige Hofhaltung. .., pp. 257-276.

Zombori, I. (szerk.) (1988). Az értelmiség Magyarországon a 16-17. században [Les intellectuels en Hongrie aux XVIe et XVIIe siècles]. Móra Ferenc Múzeum, Szeged.

Zvara, E. (2008). A Listy-család tagjainak könyvei [Les livres des différents membres de la famille Listy]. In: Hegyi, Á. and Simon, szerk., Apró cseppekből. ., 45-70.

Zvara, E. (2010). Kanizsai Pálfi János (1582-1641) könyvei Esterházy Pál gyüjteményében [La collection de livres de Pál Esterházy]. Magyar Könyvszemle, 126: 386-398.

Zvara, E. (2011). Ismert possessorok könyvei az Esterházy-könyvtárban [Les possesseurs connus des livres de la bibliothèque Esterházy]. Magyar Könyvszemle, 127: 47-71.

Zvara, E. (2012). Ceglédi Szabó Pál dunántúli református püspök könyvei [Les livres de Pál Ceglédi Szabó, évêque réformé de l'arrondissement ecclésiastique de Dunantúl]. Magyar Könyvszemle, 128: 293-318.

Zvara, E. (2020). Protestant Books of a Hungarian Catholic Aristocrat. In: Monok and Seidler, hrsg., Reformation und Bücher, pp. 159-172.

Open Access. This is an open-access article distributed under the terms of the Creative Commons Attribution 4.0 International License (https://creativecommons.org/licenses/by/4.0/), which permits unrestricted use, distribution, and reproduction in any medium, provided the original author and source are credited, a link to the CC License is provided, and changes - if any - are indicated. (SID_1) 